\title{
Temporally extended and reversible neuronal silencing with Aion
}

Silvia Rodriguez-Rozada ${ }^{1}$, Jonas Wietek ${ }^{2,3,4}$, Federico Tenedini ${ }^{5}$, Kathrin Sauter ${ }^{1,5}$, Peter Hegemann ${ }^{2}$, Peter Soba ${ }^{5,6,7}$, J. Simon Wiegert ${ }^{1 *}$

${ }^{1}$ Research Group Synaptic Wiring and Information Processing, Center for Molecular Neurobiology Hamburg, University Medical Center Hamburg-Eppendorf, 20251 Hamburg, Germany

${ }^{2}$ Institute for Biology, Experimental Biophysics, Humboldt University Berlin, D-10115 Berlin Germany

${ }^{3}$ Department of Brain Sciences, Weizmann Institute of Science, Rehovot 76100 Israel

${ }^{4}$ Department of Molecular Neuroscience, Weizmann Institute of Science, Rehovot 76100 Israel

${ }^{5}$ Research Group Neuronal Patterning and Connectivity, Center for Molecular Neurobiology Hamburg, University Medical Center Hamburg-Eppendorf, 20251 Hamburg, Germany

${ }^{6}$ LIMES Institute, Department of Molecular Brain Physiology and Behavior, University of Bonn, 53115 Bonn, Germany

${ }^{7}$ Institute of Physiology and Pathophysiology, Friedrich-Alexander-Universität ErlangenNürnberg, 91054 Erlangen, Germany

*correspondence to: simon.wiegert@zmnh.uni-hamburg.de 


\section{Abstract}

Optogenetic silencing allows to reveal the necessity of selected neuronal populations for various neurophysiological functions ranging from specific behaviors to neuronal network activity. An ideal optogenetic silencing tool should be switchable between active and inactive states with precise timing while preserving its activity in the absence of light until switched to an inactive state. Although bistable anion-conducting channelrhodopsins (ACRs) were previously engineered to reach this goal, their conducting state life time was limited to only a few minutes and some ACRs were not fully switchable. Here we report Aion, a bistable ACR displaying a long-lasting open state with a spontaneous closing time constant close to $15 \mathrm{~min}$. Moreover, Aion can be switched between the open and closed state with millisecond precision using blue and orange light, respectively. The long conducting state enables overnight silencing of neurons with minimal light exposure. We further generated trafficking-optimized versions of Aion, which show enhanced membrane localization and allow precisely timed, longlasting all-optical control of nociceptive responses in larvae of Drosophila melanogaster.

\section{Introduction}

Optogenetic manipulation of neural activity is a powerful approach to assess the function of defined neuronal populations from the subcellular to the behavioral level. While optogenetic neuronal excitation is relatively straightforward, optogenetic silencing of neural activity is limited by several constraints (Wiegert et al., 2017b). For example, suppression of neuronal activity over extended time periods requires either continuous illumination or extended activity of the inhibitory tool in absence of light.

Suppression of neuronal activity by light-driven microbial ion pumps such as Archaeorhodopsin (Arch) (Chow et al., 2010) and Halorhodopsin (NpHR) (Zhang et al., 2007) is a well-established approach. These opsins hyperpolarize neurons in response to light by actively transporting protons into (Arch) or chloride ions out of (NpHR) the cell. However, rhodopsin pumps demand continuous high-intensity illumination for efficient neuronal silencing due to their one-ion per one-photon transport ratio. Moreover, they can inactivate when illuminated for prolonged time periods (Mattis et al., 2011), which, together with their influence on local ion homeostasis (Raimondo et al., 2012; Mahn et al., 2016), limits their applicability for long-term silencing of neurons.

The development of light-activated anion-conducting channelrhodopsins (ACRs) by targeted mutagenesis of cation-conducting channelrhodopsins (CCRs) (Berndt et al., 2014; Wietek et al., 2014; Wietek et al., 2015; Berndt et al., 2016; Wietek et al., 2017) and the discovery of 
natural ACRs (Govorunova et al., 2015) introduced a new class of inhibitory optogenetic tools that overcame some of the limitations of the ion pumps. Upon illumination, ACRs silence neuronal activity by shunting membrane depolarization to the reversal potential of chloride $\left(\mathrm{E}_{\mathrm{Cl}}\right.$ ), similar to natural ionotropic $\mathrm{GABA}_{\mathrm{A}}$ receptors (Wietek et al., 2015). However, fast-cycling channels still require continuous illumination to maintain a conducting state.

Therefore, ACRs with slow off-kinetics are required for optogenetic silencing for extended periods on the scale of minutes to hours. Additionally, they need to be switchable to their nonconducting state to enable temporally precise on- and offset of the silencing period. ACRs with slow off-kinetics are furthermore relevant in long-term optogenetic experiments to prevent tissue-heating and phototoxicity by continuous illumination, particularly in the short wavelength range (Stujenske et al., 2015; Owen et al., 2019). The slowed-down photocycle greatly enhances the operational light sensitivity of engineered ACRs for effective inhibition due to the prolonged open-state and the resulting accumulation of chloride $\left(\mathrm{Cl}^{-}\right)$conducting ACRs during the illumination period.

In ChR2, the two amino acids C128 and D156 constitute the DC-gate, which is required for the reprotonation of the Schiff-base and subsequent termination of the conducting state. Mutations at these residues yielded slow-cycling, bistable CCRs, which could be toggled between a conducting and a closed state with light of different wavelengths (Berndt et al., 2009; Yizhar et al., 2011). To extend the temporal range for inhibition, slow-cycling ACRs with long-lasting conducting states were generated using a similar strategy (Berndt et al., 2014; Wietek et al., 2014; Sineshchekov et al., 2015; Berndt et al., 2016; Wietek et al., 2017). Introduction of the analogous $C 128 \mathrm{~A}$ mutation in engineered $A C R$ s yielded the second-generation step-function ACRs SwiChR++ (Berndt et al., 2016) and Phobos ${ }^{\text {CA }}$ (Wietek et al., 2017). SwiChR++ and Phobos ${ }^{\mathrm{CA}}$ feature closing time constants of $115 \pm 9 \mathrm{~s}$ and $249 \pm 10 \mathrm{~s}$, respectively, and channel closing could be strongly accelerated with orange light illumination $(<0.5 \mathrm{~s})$. These engineered bistable ACRs were used to reversibly inhibit various types of neurons in Drosophila larvae (Wietek et al., 2017) and mice (Berndt et al., 2016). Similarly, cysteine-alanine substitution in the potent, natural GtACR1 (GtACR1CA) has been shown to enable inhibition of neuronal spiking in mammalian neurons for at least $10 \mathrm{~s}$ after a brief light stimulus (Govorunova et al., 2018), as well as light-induced body wall muscle relaxation when expressed in motor neurons of C. elegans (Bergs et al., 2018). However, GtACR1 ${ }^{\text {CA }}$ is not fully switchable, limiting precise off-kinetics and temporal control of inhibition (Govorunova et al., 2018).

To further explore the possibilities of generating slow-cycling ACRs and to temporally extend their open state, we systematically mutated amino acids in the DC-gate of Phobos ${ }^{\mathrm{CA}}$ and 
improved the trafficking properties in neurons. Of the various D156 mutations tested, Phobos ${ }^{\text {CADC }}$ expressed well in neurons, showed enhanced photocurrents and a vastly extended life-time of the conducting state compared to its parental Phobos ${ }^{\mathrm{CA}}$. We therefore named this variant "Aion" after the Greek god of unbounded time (Levi, 1944). Importantly, the photoswitching ability is preserved in Aion. It can be photoconverted to a fully closed state with light around $590 \mathrm{~nm}$, granting precisely timed termination of silencing. We characterized the biophysical properties of Aion in HEK cells and show its silencing ability in organotypic hippocampal slice cultures, permitting faithful silencing of neurons over many hours with short light pulses spaced many minutes apart. We further show the utility of Aion in vivo by inhibiting nociceptive circuit function in Drosophila melanogaster larvae over extended time periods in all-optical experiments. Aion thus broadens the available toolkit of optogenetic silencers in the temporal domain, opening new possibilities for optical manipulation of neuronal circuits.

\section{Results}

\section{Engineering of Aion and biophysical characterization in HEK cells}

Based on the previously engineered blue shifted, step-function ACR Phobos ${ }^{\mathrm{CA}}$ (Wietek et al., 2017), we systematically mutated the residue D156 (Fig. 1A), which together with C128 forms the DC-gate, a structural component important for channel gating kinetics in the parent $\mathrm{ChR}$ C1C2 (Kato et al., 2012). We exchanged D156 for either cysteine (C), asparagine (N), serine (S), or histidine (H) (Dawydow et al., 2014; Duan et al., 2019). From all tested variants, only D156N (Phobos ${ }^{\mathrm{CADN}}$ ) and D156C (Phobos ${ }^{\mathrm{CADC}}$, Aion) yielded functionally expressed ACRs in neurons (Fig. S1). We therefore characterized these variants in detail and compared them to the previously published slow-cycling ACRs Phobos ${ }^{\mathrm{CA}}$ and GtACR1 ${ }^{\mathrm{CA}}$.

To assess the biophysical parameters of Aion and Phobos ${ }^{\mathrm{CADN}}$ and to benchmark them against Phobos ${ }^{\mathrm{CA}}$ and GtACR1 ${ }^{\mathrm{CA}}$ we transiently expressed them in HEK-293 cells and measured lightinduced photocurrents in voltage-clamp (Fig.1, Fig. S2). With all opsins, long lasting photocurrents were detected following brief illumination $(20 \mathrm{~ms})$ with blue or green light (Fig. 1B). Extending the illumination period to $500 \mathrm{~ms}$ revealed different modes of desensitization for all variants (decline of the peak current to stationary level, Fig. S2A, B). We analyzed the peak $\left(I_{p}\right)$ and stationary photocurrent $30 \mathrm{~s}$ post illumination $\left(I_{30 s}\right)$, normalized to cell capacity. Photocurrents of Phobos ${ }^{\mathrm{CADN}}$ were smaller compared to the parental Phobos ${ }^{\mathrm{CA}}$, while Aion displayed increased photocurrent densities (Fig. 1C). For the parental Phobos ${ }^{\mathrm{CA}}$, both currents where similar $\left(I_{p}=39 \pm 4\right.$ and $\left.I_{30 s}=33 \pm 4 \mathrm{pA} / \mathrm{pF}\right)$. The calculated desensitization $(15 \pm 1 \%)$ could be attributed to the slow channel closure as for Phobos ${ }^{\mathrm{CA}}$ no short-living initial photocurrent was observed (Fig. S2B). In contrast, both, Phobos ${ }^{\mathrm{CADN}}$ and Aion displayed peak 
photocurrent that desensitized during the 500 ms illumination (Fig. 1B), accounting for a $30 \pm$ $1 \%$ and $38 \pm 2 \%$ overall reduction of photocurrents after $30 \mathrm{~s}$, respectively (Fig. 1C). In contrast, for GtACR1 $1^{\mathrm{CA}}$ desensitization was observed only after termination of the $500 \mathrm{~ms}$ illumination period (Fig. S2C), leading to a pronounced inactivation (74 $\pm 2 \%$ ), while peak photocurrent densities were highest $(105 \pm 20 \mathrm{pA} / \mathrm{pF})$ among all tested slow-cycling ACR variants (Fig. 1C). The closing time constants were $61 \pm 5 \mathrm{~s}$ (GtACR1 ${ }^{\mathrm{CA}}$ ), $186 \pm 14 \mathrm{~s}$ (Phobos $^{\mathrm{CA}}$ ), $338 \pm 36 \mathrm{~s}$ (Phobos ${ }^{\mathrm{CADN}}$ ) and $892 \pm 82 \mathrm{~s}$ (Aion, Fig. 1D, E) and could be readily accelerated with orange light for all Phobos-based variants, leading to complete termination of $\mathrm{Cl}^{-}$conductivity (Fig. S2A, C-E). In contrast, for GtACR1CA only a small reduction of the conductance (to $70 \pm 2 \%$ of the initial current) was achieved, when red light (Govorunova et al., 2018) was applied $2 \mathrm{~s}$ after GtACR $1^{\mathrm{CA}}$ activation. Delaying red light application to $30 \mathrm{~s}$ caused reactivation and even increased photocurrent amplitudes (Fig. S2A).
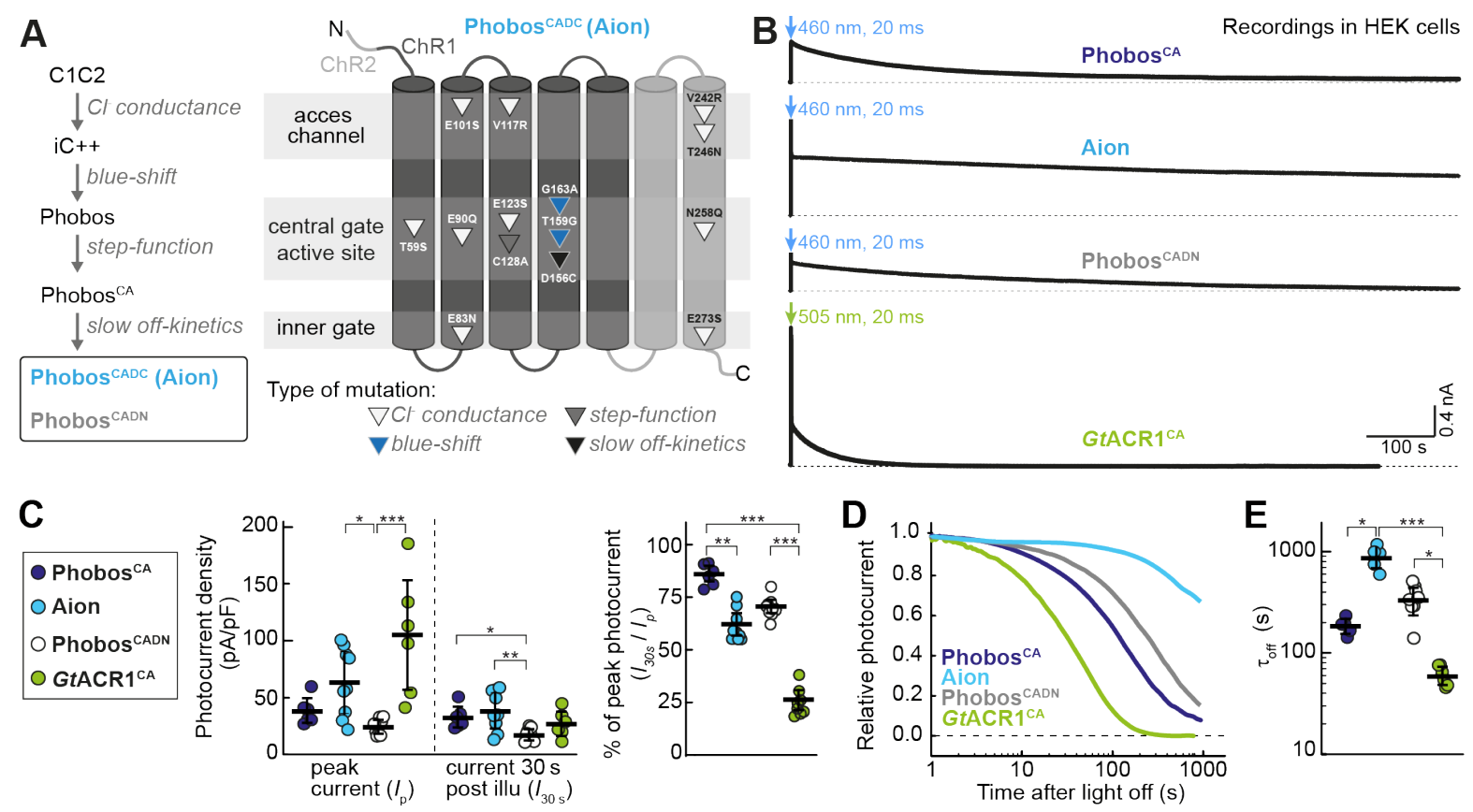

143

144

145

146

147

148

149

150

151

152

153

154

155

156

Figure 1. Development of Aion and Phobos ${ }^{\mathrm{CADN}}$ and photocurrent characterization in HEK cells. (A) Left: Engineering strategy yielding Aion and Phobos CADN, two new blue-shifted, step-function ACRs with temporally extended conducting states. Mutation of the D156 residue to either $\mathrm{C}$ or $\mathrm{N}$ (yielding Aion and Phobos ${ }^{\mathrm{CADN}}$, respectively) greatly slows down the closing kinetics of the ACRs compared to its parental construct Phobos ${ }^{\mathrm{CA}}$. The generated variants are highlighted by a black frame. Right: Schematic of Aion indicating point mutations (triangles) at the relative position within the respective transmembrane helix. (B) Representative photocurrent traces of the slow-cycling ACRs Phobos ${ }^{C A}$, Aion, Phobos ${ }^{\text {CADN }}$, and GtACR $1^{\mathrm{CA}}$ activated by a short $20 \mathrm{~ms}$ light pulse at indicated wavelengths and irradiance of 3.35 $\mathrm{mW} / \mathrm{mm}^{2}(460 \mathrm{~nm})$ and $3.14 \mathrm{~mW} / \mathrm{mm}^{2}(505 \mathrm{~nm})$. (C) Left: quantification of peak photocurrent $\left(I_{p}\right)$ and photocurrent $30 \mathrm{~s}$ post illumination $\left(I_{30 \mathrm{~s}}\right)$ for each ACR. Right: photocurrent ratio at $30 \mathrm{~s}$ compared to the peak. (D) Normalized photocurrent after light shutoff. (E) Closing time constants ( $\left.\tau_{\text {off }}\right)$ for each ACR. For (C) and (E), black lines correspond to mean values \pm SEM, and circles are single measurement data points ( $\mathrm{n}_{\text {PhobosCA }}=5-6$ cells, $\mathrm{n}_{\text {Aion }}=5-10$ cells, $\mathrm{n}_{\text {PhobosCADN }}=8-9$ cells, $\mathrm{n}_{\text {GtACR1CA }}=6$ cells). KruskalWallis test with Dunn's multiple comparisons test, ${ }^{*} p<0.05,{ }^{* *} p<0.01,{ }^{* * *} p<0.001$. 
157 In summary, Phobos ${ }^{\text {CADN }}$ and Aion displayed extended closing time constants compared to

158 Phobos ${ }^{\mathrm{CA}}$. Aion showed the longest-lasting conducting state of all currently known ACRs, while 159 preserving a large photocurrent density and, in contrast to the potent GtACR1CA, was fully 160 switchable between the open and closed state.

161 Functional characterization of Aion, Phobos ${ }^{\text {CADN }}$, and GtACR ${ }^{\text {CA }}$ in CA1 pyramidal 162 neurons

163 Next, we evaluated the functionality of Aion in comparison to Phobos ${ }^{\text {CADN }}$ and GtACR $1^{\text {CA }}$ in 164 CA1 pyramidal neurons of rat organotypic hippocampal slice cultures. All three citrine-labelled 165 ACRs showed high expression and membrane-localized distribution (Fig. 2A). However, 166 GtACR1CA did not traffic evenly throughout the cell and displayed patchy and punctate 167 accumulations along the neuronal arbors (Fig. 2A iii).

169 Using whole-cell patch-clamp recordings, we measured light-induced ACR-mediated $\mathrm{Cl}^{-}$ 170 currents. Opsin-expressing neurons were held at a depolarized membrane voltage (-35 $\mathrm{mV})$ 171 with respect to the $\mathrm{E}_{\mathrm{Cl}}$. Photostimulation of ACRs thus results in outward-directed 172 photocurrents upon entry of $\mathrm{Cl}^{-}$ions. A short light pulse at the peak activation wavelength (460 $173 \mathrm{~nm}$ for Aion and Phobos ${ }^{\mathrm{CADN} ;} 525 \mathrm{~nm}$ for $\mathrm{GtACR} 1^{\mathrm{CA}}$ ) elicited $\mathrm{Cl}^{-}$photocurrents that were 174 maintained for several seconds to minutes after light offset (Fig. 2B). While all ACRs showed 175 similar peak current amplitudes (Fig. 2C), Phobos ${ }^{C A D N}$ - and GtACR1 ${ }^{\text {CA-mediated } \mathrm{Cl}^{-}}$ 176 photocurrents decayed faster than Aion-mediated currents. Peak-normalized mean 177 photocurrent amplitudes dropped from $25.6 \pm 1.2 \%$ at $30 \mathrm{~s}$ to $14.6 \pm 1.1 \%$ at $120 \mathrm{~s}$ after 178 photostimulation of Phobos ${ }^{\text {CADN }}$ (120 s / 30 s ratio: $59.4 \pm 10.1 \%$ ). In GtACR $1^{\text {CA }}$-expressing 179 cells stationary photocurrents were reduced from $20.2 \pm 1.1 \%$ at $30 \mathrm{~s}$ to $6.1 \pm 1.8 \%$ at $120 \mathrm{~s}$ 180 after light stimulation (120 s / 30 s ratio: $29.5 \pm 8.2 \%$ ) (Fig. 2D, E). In contrast, Aion-mediated 181 stationary $\mathrm{Cl}^{-}$currents were relatively stable over the whole 3-minutes recording (Fig. 2B, i), 182 with a 120 s/30s photocurrent ratio of $81.3 \pm 4.3 \%(22.1 \pm 1.2 \%$ and $17.7 \pm 1.1$ of peak 183 photocurrent at $30 \mathrm{~s}$ and $120 \mathrm{~s}$ after photostimulation, respectively) (Fig. 2D, E). 


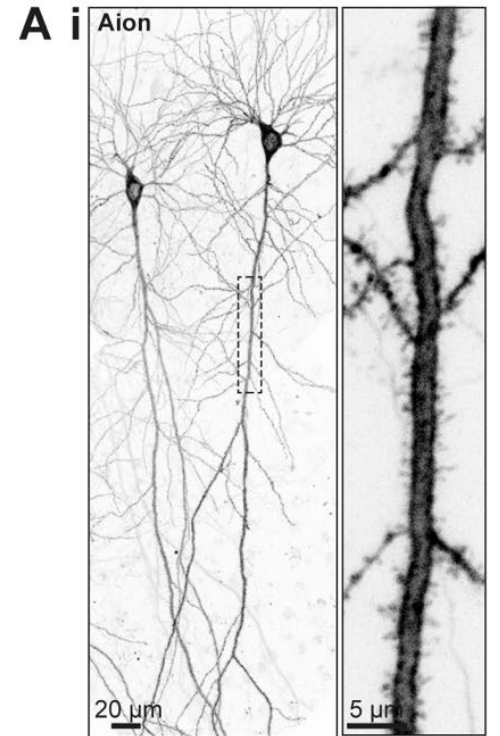

B
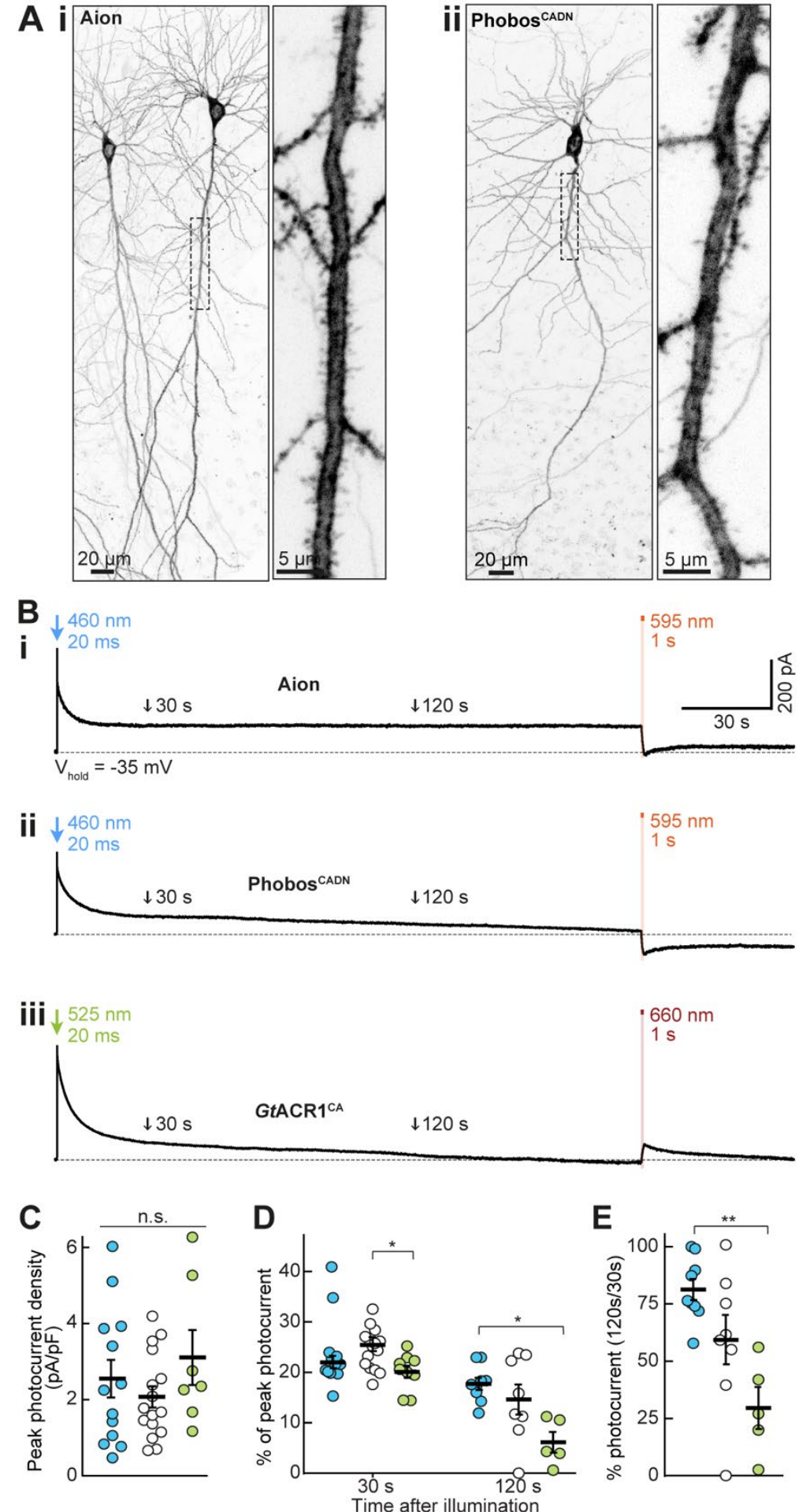
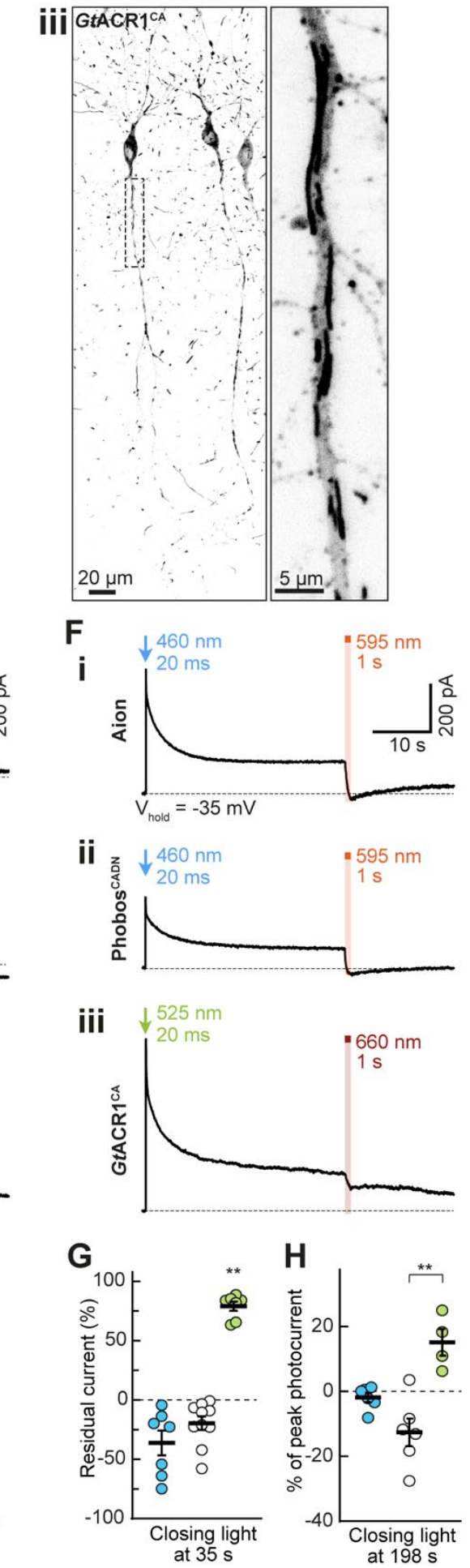

Figure 2. Expression and photocurrents of Aion, Phobos ${ }^{\mathrm{CADN}}$, and GtACR1 ${ }^{\mathrm{CA}}$ in CA1 pyramidal neurons. (A) Maximum-intensity projection images of two-photon stacks showing expression of Aion (i) Phobos $^{\text {CADN }}$ (ii) and GtACR1 $1^{\text {CA }}$ (iii) in CA1 pyramidal neurons of rat organotypic hippocampal slice cultures. Fluorescence intensity is shown as inverted gray values. Insets show magnified view of the apical dendrite. (B) Representative photocurrent traces of Aion (i), Phobos ${ }^{\mathrm{CADN}}$ (ii) and GtACR1 ${ }^{\mathrm{CA}}$ (iii), evoked by a $20 \mathrm{~ms}$ light pulse at the respective peak activation wavelength (460 $\mathrm{nm}$ for Aion and Phobos $^{\text {CADN }}, 525 \mathrm{~nm}$ for GtACR1 ${ }^{\mathrm{CA}}$ ) and equal irradiance of $10 \mathrm{~mW} / \mathrm{mm}^{2}$. Channel closing was accelerated with red-shifted light $\left(1 \mathrm{~s}, 10 \mathrm{~mW} / \mathrm{mm}^{2}, 595 \mathrm{~nm}\right.$ for Aion and Phobos ${ }^{\text {CADN }}, 660 \mathrm{~nm}$ for GtACR $1^{\mathrm{CA}}$ ) at $197 \mathrm{~s}$ after channel opening. Note that red light at $198 \mathrm{~s}$ elicited partial opening of 
GtACR $1^{\mathrm{CA}}$ instead of closing, indicated by an outward current after light stimulation. The black arrows at 30 and $120 \mathrm{~s}$ after channel opening indicate the time points at which stationary photocurrent amplitudes were quantified in C-E. (C) Quantification of peak photocurrent density for Aion, Phobos ${ }^{\text {CADN }}$ and GtACR1 ${ }^{\text {CA }}$. (D) Quantification of photocurrent amplitude at $30 \mathrm{~s}$ and $120 \mathrm{~s}$ after channel opening with respect to peak current. (E) Photocurrent ratio at $120 \mathrm{~s}$ compared to $30 \mathrm{~s}$. (F) Same as (B) but channel closing was accelerated $35 \mathrm{~s}$ after opening. (G) Residual current upon channel closing $35 \mathrm{~s}$ after opening. Photocurrent amplitude was measured in the $5 \mathrm{~s}$ before and after the closing light pulse. (H) Quantification of photocurrent amplitude upon channel closing $198 \mathrm{~s}$ after opening with respect to the peak photocurrent. For (C-E, G-H), mean values \pm SEM are shown (black lines) together with single measurement data points (circles, $n=5-16$ cells). Kruskal-Wallis test with Dunn's multiple comparisons test, ${ }^{*} p<0.05,{ }^{* *} p<0.01$.

Similar to their parental construct Phobos ${ }^{\mathrm{CA}}$ (Wietek et al., 2017), and consistent with the measurements in HEK cells (Fig. S2), we could accelerate the closing of both Aion and Phobos ${ }^{\mathrm{CADN}}$ at any time point by illuminating with orange light $(595 \mathrm{~nm})$. Absence of residual photocurrents after orange-light illumination suggests full channel closing (Fig. 2B i and ii, F i and ii, G-H). However, this was not the case for GtACR1 ${ }^{\mathrm{CA}}$, for which $1 \mathrm{~s}$ illumination with red light $(660 \mathrm{~nm})$ at $35 \mathrm{~s}$ after channel opening reduced the $\mathrm{Cl}^{-}$current only by $21 \%$ (Fig. F iii, G). Moreover, red light stimulation $198 \mathrm{~s}$ after channel opening, a time by which GtACR $1^{\mathrm{CA}}$ was mostly closed via thermal relaxation of the open state, elicited a $\mathrm{Cl}^{-}$current with an amplitude of $17.2 \pm 3.6 \%$ compared to the green-light induced peak current (Fig. $2 \mathrm{~B}$ iii, H). This suggests that red light likely brings $\mathrm{GtACR} 1^{\mathrm{CA}}$ to an intermediate conducting state in the photocycle, rather than to the dark ground state.

Having shown that brief photoactivation of Aion and Phobos ${ }^{\text {CADN }}$ resulted in sustained $\mathrm{Cl}^{-}$ conductance, we next asked whether these slow-cycling step-function ACRs are suitable to block action potentials (APs) after a short light pulse and whether this block could be reverted with red-shifted illumination (Fig. 3, Fig. S3). Both Aion and Phobos ${ }^{\mathrm{CADN}}$ efficiently blocked depolarization-induced APs during a $40 \mathrm{~s}$ period following a $20 \mathrm{~ms}$ blue light pulse. Furthermore, we could recover AP firing with high temporal precision after closing the respective ACR with orange light (Fig. 3A, Fig. S3A). While activation of GtACR1 ${ }^{\text {CA }}$ (20 ms, $525 \mathrm{~nm}$-light pulse) also resulted in sustained inhibition of current-evoked APs, firing could not be restored upon red light illumination (Fig. 3B). This is consistent with the photocurrent recordings in neurons and HEK cells, which showed only partial reduction of GtACR1CA conductance upon red illumination (Fig. 2F iii, G; Fig. S2A, D). Thus, illumination with red light was leaving a residual $\mathrm{Cl}^{-}$conductance big enough to prevent AP recovery and, unlike Aion and Phobos ${ }^{\mathrm{CADN}}$, GtACR $1^{\mathrm{CA}}$ does not allow precisely timed termination of silencing.

To compare the silencing performance of the three step-function ACRs more quantitatively, we measured their capability to positively shift the rheobase (i.e. the minimum current required 
233 to elicit an AP). We repeatedly injected depolarizing current ramps into ACR-expressing CA1

234 neurons at an interval of $0.2 \mathrm{~Hz}$ for one minute (see Materials and Methods for further details).

235 For each ramp, the injected current at the time of the first AP was defined as the rheobase. To

236 open the respective ACR a $1 \mathrm{~s}$ light pulse was applied after the first current ramp (Fig. 3C, G;

237 Fig. S3B). All three ACRs shifted the rheobase towards larger currents for several seconds

238 after light stimulation, albeit with different efficacy. Phobos ${ }^{\mathrm{CADN}}$ showed the weakest silencing

239 capacity, only shifting the rheobase by $157.5 \pm 32.7 \mathrm{pA}$ immediately after illumination, which

240 was not sufficient to completely block APs (Fig. S3C, D). Aion-mediated inhibition was more

241 potent, yielding a rheobase shift of $463.2 \pm 98.0$ pA which was maintained throughout the 47

242 s recording period after light stimulation (Fig. 3D). As a result, the median number of current-

243 evoked APs was suppressed by $85.3 \%$ (range: $80.0-93.3 \%$ ), with complete AP block in 2

244 out of 7 cells (Fig. 3E). GtACR1 ${ }^{\text {CA }}$ showed the strongest inhibition immediately after light

245 stimulation, shifting the rheobase by $601.3 \pm 162.9 \mathrm{pA}$ and fully suppressing APs in 4 out of 6

246 cells. However, as expected from the faster closing time constant, GtACR1CA silencing

247 capacity was not sustained over the time course of $47 \mathrm{~s}$. The shift in rheobase dropped to

$248318.2 \pm 142.6 \mathrm{pA}$ (a reduction of $52.9 \%$ ), yielding $56.2 \%$ (range: $0.0-100 \%$ ) suppression of

249 APs (Fig. 3H, I). All three ACRs significantly decreased AP firing starting at an irradiance of

$2500.1 \mathrm{~mW} / \mathrm{mm}^{2}$, with GtACR1 ${ }^{\mathrm{CA}}$ showing complete block of APs already at $0.01 \mathrm{~mW} / \mathrm{mm}^{2}$ in 2

251 out of 7 cells (Fig. 3F, J; Fig. 3E). These results match the photocurrent recordings (Fig. 2B-

252 E) and indicate that, while GtACR1 ${ }^{C A}$ shows more potent inhibition immediately after light

253 offset, Aion shows the best combination of acute and sustained inhibition of neuronal spiking.

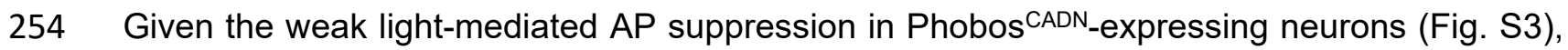

255 we only further assessed Aion and GtACR $1^{\mathrm{CA}}$ for their applicability as long-term silencing tools. 


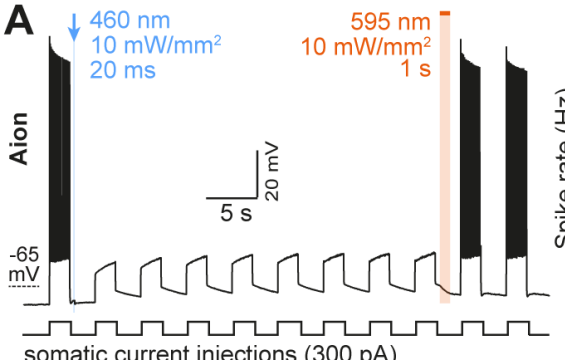
somatic current injections (300 pA)

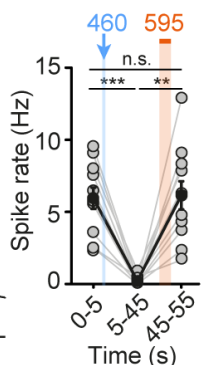

Time (s)
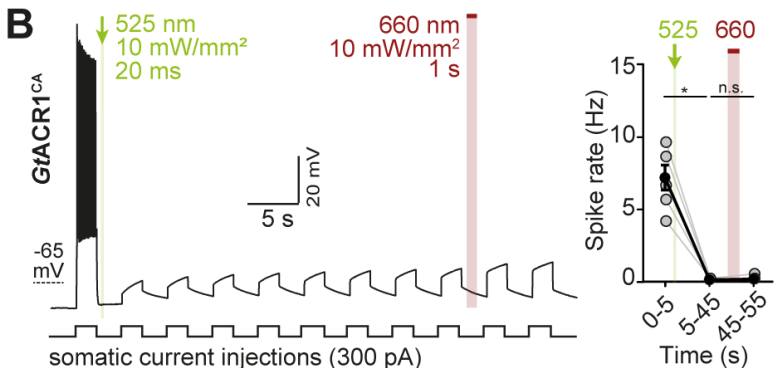

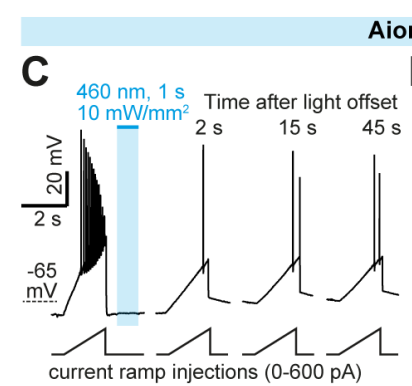

D

$10 \mathrm{~mW} / \mathrm{mm}^{2}$

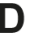

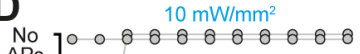

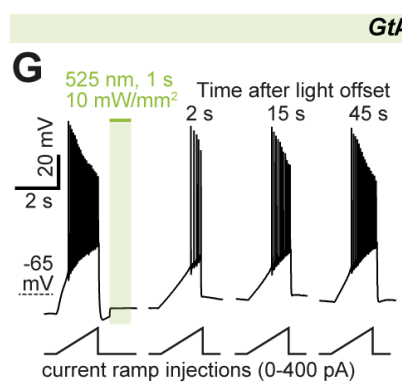

GtACR1 1 A

$H_{N}$

$10 \mathrm{~mW} / \mathrm{mm}$
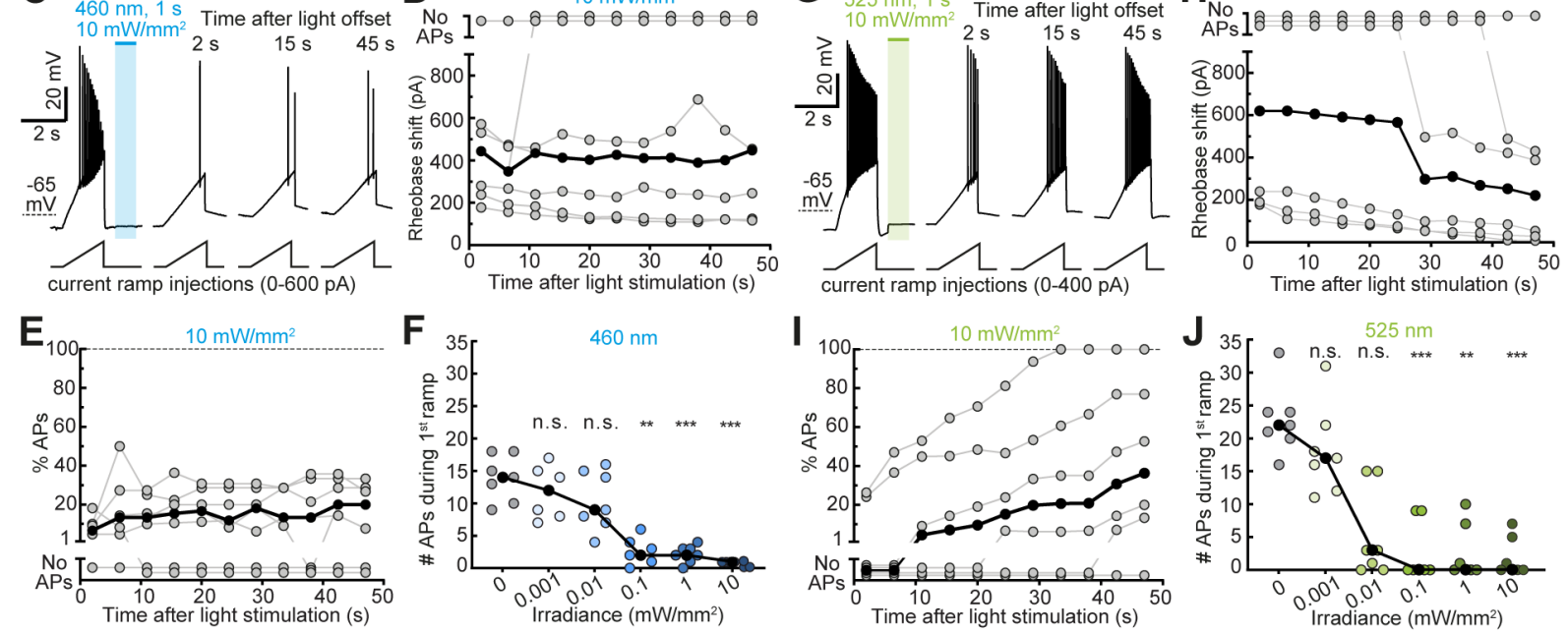

Figure 3. Silencing efficiency of Aion and GtACR1 ${ }^{\mathrm{CA}}$ in CA1 pyramidal neurons. (A) Left: Membrane voltage trace showing reversible suppression of depolarization-induced action potentials (APs) by photoswitching Aion between open and closed state with a blue $\left(460 \mathrm{~nm}, 20 \mathrm{~ms}, 10 \mathrm{~mW} / \mathrm{mm}^{2}\right)$ and an orange light pulse $\left(595 \mathrm{~nm}, 1 \mathrm{~s}, 10 \mathrm{~mW} / \mathrm{mm}^{2}\right)$, respectively. Right: Quantification of spike rate during current injection at indicated time intervals: before channel opening (0-5 s), after channel opening (5-45 s), and after channel closing (45-55 s) in Aion-expressing CA1 neurons ( $\mathrm{n}=10$ cells). (B) Same as (A) but for neurons expressing GtACR $1^{C A}(n=5$ cells). Channel was opened with a green $(525 \mathrm{~nm}$, $20 \mathrm{~ms}, 10 \mathrm{~mW} / \mathrm{mm}^{2}$ ) light pulse. Note that in GtACR $1^{\mathrm{CA}}$-expressing cells AP firing could not be recovered immediately after illumination with red light $\left(660 \mathrm{~nm}, 1 \mathrm{~s}, 10 \mathrm{~mW} / \mathrm{mm}^{2}\right)$. (C) Current ramps were injected into Aion-expressing neurons to induce APs before and after illumination with a short blue light pulse $\left(460 \mathrm{~nm}, 1 \mathrm{~s}\right.$, irradiances from 0.001 to $\left.10 \mathrm{~mW} / \mathrm{mm}^{2}\right)$. For each ramp, the injected current at the time of the first AP was defined as the rheobase. Example membrane voltage traces are shown for the trial in which a light intensity of $10 \mathrm{~mW} / \mathrm{mm}^{2}$ was used. (D) Quantification of the rheobase shift and (E) the relative change in the number of current ramp-evoked APs over $47 \mathrm{~s}$ after light stimulation $(460 \mathrm{~nm}, 1$ $\left.\mathrm{s}, 10 \mathrm{~mW} / \mathrm{mm}^{2}\right)(\mathrm{n}=7$ cells). (F) Number of APs evoked during the first current ramp after opening of Aion with $1 \mathrm{~s}$ blue light at indicated irradiances. Significant AP block was achieved at $0.1 \mathrm{~mW} / \mathrm{mm}^{2}(\mathrm{n}=$ 7 cells). (G-J) Same experiment as shown in (C-F) except that CA1 neurons expressed GtACR $1^{\text {CA }}(\mathrm{n}=$ 6-7 cells) and $525 \mathrm{~nm}$-light was used for channel opening. Note that GtACR $1^{\mathrm{CA}}$ silencing efficacy decayed already within the $1^{\text {st }}$ minute after light stimulation $(I, J)$. For $(A, B, D-F$, and $H-J)$ filled circles represent single measurement data points and black circles correspond to medians, Friedman test, * $p$ $<0.05,{ }^{* *} p<0.01,{ }^{* * *} p<0.001$, n.s. $=$ not significant.

So far, we evaluated silencing of APs over a relatively short time period, which was already achievable with previously published slow-cycling ACRs. We now aimed to test neuronal silencing over time periods of many minutes and up to 12 hours. First, we quantified the effects of Aion and GtACR1 $1^{\mathrm{CA}}$ to assess their suitability for long-term silencing experiments. In this 
context, Aion reliably blocked depolarization-induced APs over a 10-minute period when activated by 2 brief light pulses $\left(1 \mathrm{~s}, 460 \mathrm{~nm}, 10 \mathrm{~mW} / \mathrm{mm}^{2}\right.$ ) delivered 5 minutes apart (Fig. 4A). Accordingly, the Aion-mediated decrease in membrane depolarization of $54.5 \%$ (range: 48.2 - $62.4 \%$ ) was stable for 5 min after light stimulation and was sufficient to block all APs (Fig. $4 \mathrm{~B}, \mathrm{C})$. In contrast, in neurons expressing GtACR $1^{\mathrm{CA}}$ current-evoked AP firing was generally recovered within the first minute (median $58.8 \mathrm{~s}$, range: $20.5-201.6 \mathrm{~s}$ ) after opening of the ACR by a short light pulse $\left(1 \mathrm{~s}, 525 \mathrm{~nm}, 10 \mathrm{~mW} / \mathrm{mm}^{2}\right)$, and the initial reduction of $59.3 \%$ (range: $52.7 \%-66.9 \%$ ) in membrane depolarization went back to baseline values after $3.6 \pm$ 0.3 min (Fig. 4D-F). Therefore, reliable AP suppression with GtACR $1^{\text {CA }}$ for time periods longer than 1 minute requires light stimulation protocols with shorter interstimulus intervals, and consequently more frequent light exposure, as compared to Aion.

Given that brief light stimulations every 5 minutes allowed reliable suppression of AP firing in Aion-expressing CA1 neurons, we next asked whether Aion is suitable for neuronal silencing over several hours using 5-min long dark interstimulus intervals. Neurons were stimulated overnight $(\mathrm{O} / \mathrm{N})$ inside the incubator in a custom-made blue-LED chamber (Fig. 4G). Wholecell current-clamp recordings in Aion-expressing cells after $12 \mathrm{~h}$ of light stimulation showed that depolarization-induced APs ( $2 \mathrm{~s}$ current injections every $4.5 \mathrm{~s}$ ) were reliably blocked for at least $5 \mathrm{~min}$ by activating Aion with a single blue light pulse $\left(3 \mathrm{~s}, 0.3 \mathrm{~mW} / \mathrm{mm}^{2}\right.$, same conditions as $\mathrm{O} / \mathrm{N}$ stimulation in the incubator) (Fig. 4G, H). Thus, Aion was still fully functional and silencing was efficient after $\mathrm{O} / \mathrm{N}$ activation in the incubator.

303 To determine whether such long-term Aion-mediated $\mathrm{Cl}^{-}$conductance compromised cell health, we measured passive and active membrane parameters of Aion-expressing neurons after the $\mathrm{O} / \mathrm{N}$ protocol. Overall, no significant differences were observed compared to three different control conditions: non-transfected or citrine-expressing CA1 cells that received O/N photostimulation, or Aion-expressing neurons that were not illuminated (Fig. 4I). Only the resting membrane potential was mildly depolarized in citrine-only (but not Aion) cells. This suggests that activation of Aion for $12 \mathrm{~h}$ under the indicated conditions was well tolerated by CA1 pyramidal neurons and did not lead to obvious alterations of $\mathrm{Cl}^{-}$homeostasis. 

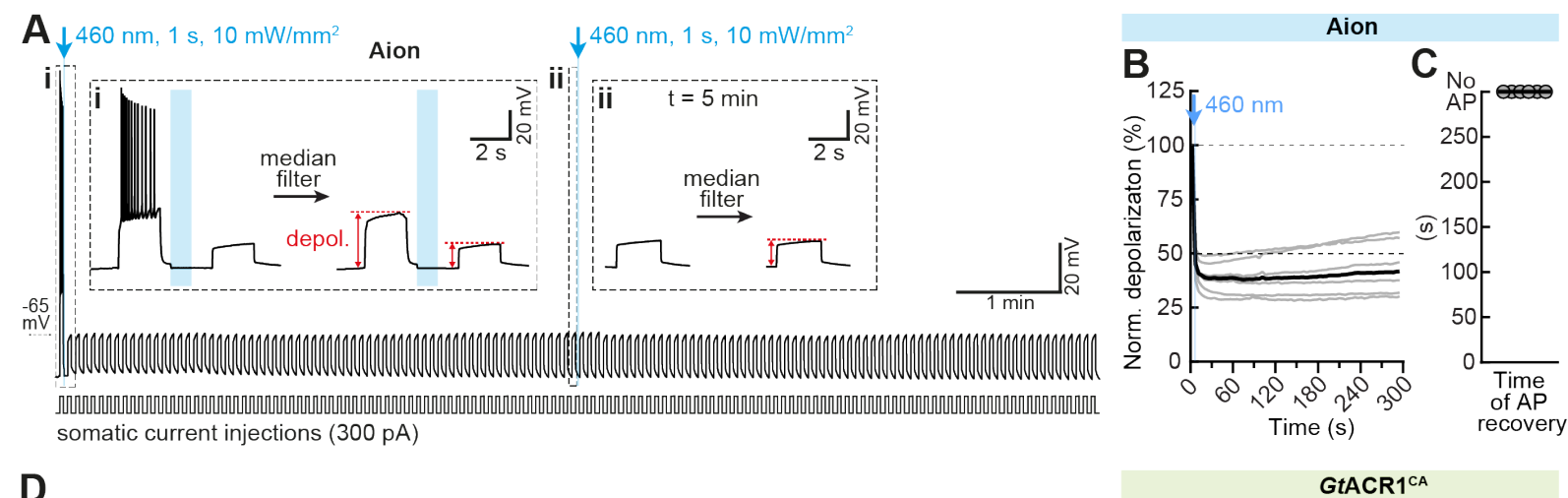

D
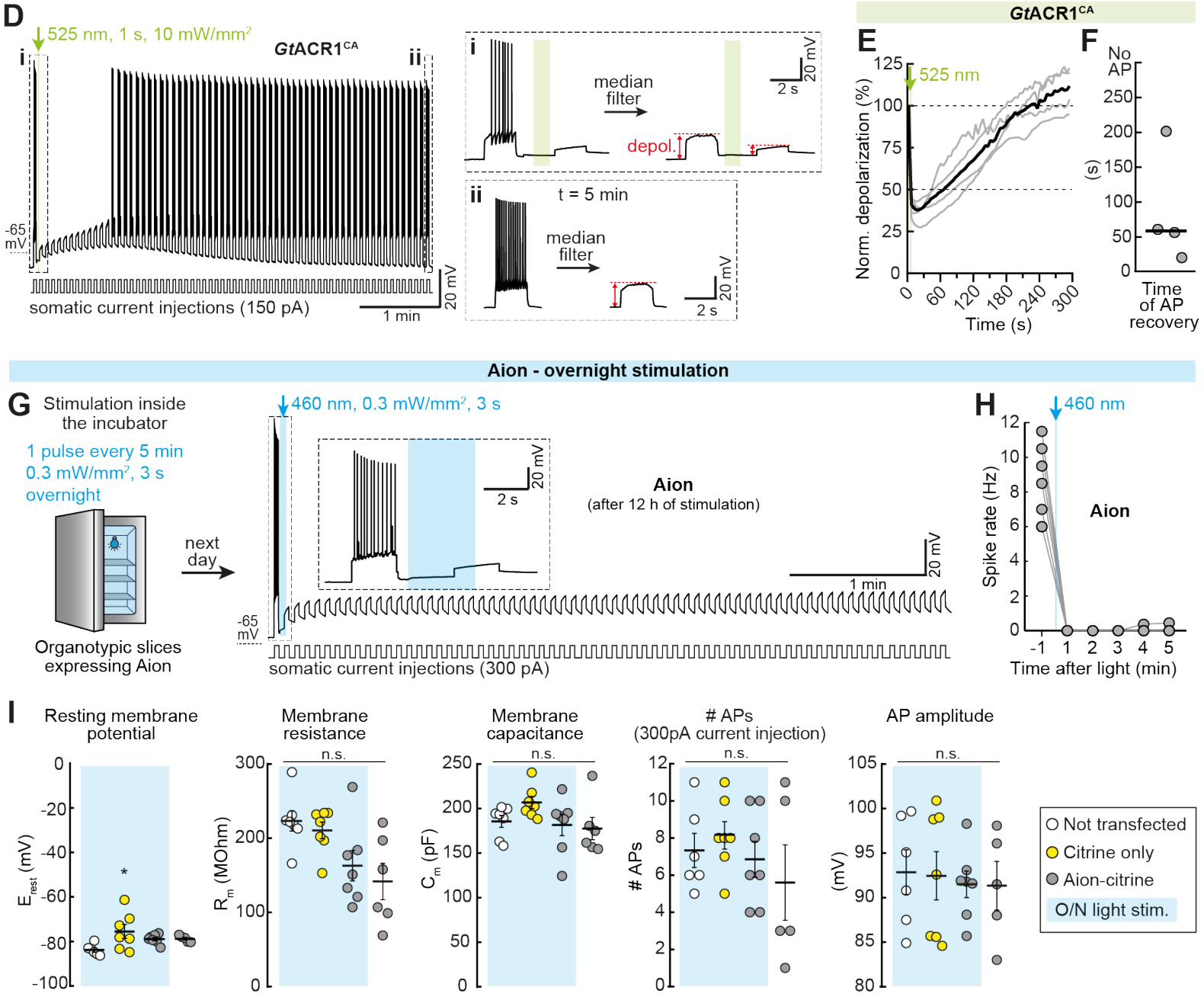

Figure 4. Long-term silencing with Aion and GtACR1 ${ }^{\text {CA }}$ in CA1 pyramidal neurons. (A) Aion silencing capacity was evaluated over 10 minutes. Example membrane voltage trace of an Aionexpressing CA1 neuron showing reliable suppression of depolarization-induced APs $(2 \mathrm{~s}$ current injections every $4.5 \mathrm{~s}$ ) for 10 min by activating Aion with 2 short blue light pulses spaced 5 min apart $\left(460 \mathrm{~nm}, 1 \mathrm{~s}, 10 \mathrm{~mW} / \mathrm{mm}^{2}\right)$. (i, ii) Insets show magnified view of the membrane potential at the indicated time points. Voltage traces were median-filtered to calculate the change in membrane depolarization after light stimulation of Aion (as shown by the red arrows). (B) Quantification of Aion-mediated change in membrane depolarization over a time period of $5 \mathrm{~min}$ after light stimulation $\left(460 \mathrm{~nm}, 1 \mathrm{~s}, 10 \mathrm{~mW} / \mathrm{mm}^{2}\right)$ as shown in (A). Grey traces correspond to single neurons and black trace shows the median $(n=6$ cells). (C) Time at which the $1^{\text {st }}$ current-evoked AP occurred after opening of Aion. Note that Aion reliably blocked all APs for 5 min after light stimulation. Grey circles represent single measurement data points and black line corresponds to median ( $n=6$ cells). (D) GtACR $1^{\mathrm{CA}}$ silencing capacity was evaluated over 5 minutes. Example membrane voltage trace of a GtACR $1^{\text {CA }}$-expressing CA1 neuron after activation of 
GtACR $1^{\text {CA }}$ with a short green light pulse $\left(525 \mathrm{~nm}, 1 \mathrm{~s}, 10 \mathrm{~mW} / \mathrm{mm}^{2}\right)$. (i, ii) same as (A, i-ii) but for $\operatorname{GtACR}^{\mathrm{CA}}$. (E, F) Same as (B, C) but for $\operatorname{GtACR}^{\mathrm{CA}}\left(\mathrm{n}=4 \mathrm{cells} ; 525 \mathrm{~nm}, 1 \mathrm{~s}, 10 \mathrm{~mW} / \mathrm{mm}^{2}\right)$. Note that the change in membrane depolarization went back to baseline approx. $3.5 \mathrm{~min}$ after light stimulation $(E)$ and neurons started firing within the first $200 \mathrm{~s}$ after light stimulation $(F)$. (G) Left: Organotypic slices with CA1 cells expressing Aion were stimulated overnight $(\mathrm{O} / \mathrm{N})$ in a custom-made LED chamber inside the incubator ( $3 \mathrm{~s} 460-\mathrm{nm}$ light pulse every $5 \mathrm{~min}, 0.3 \mathrm{~mW} / \mathrm{mm}^{2}$ ). Right: example membrane voltage trace of an Aion-expressing CA1 neuron recorded after $12 \mathrm{~h}$ of light stimulation in the incubator. Inset shows magnified view of the membrane potential during light stimulation. (H) Quantification of spike rate before and during the 5 minutes following light stimulation. (I) Resting membrane potential, membrane resistance, membrane capacitance, number of APs evoked by somatic current injection (300 pA, 500 $\mathrm{ms}$ ) and amplitude of the $1^{\text {st }} \mathrm{AP}$ in Aion-expressing cells after $12 \mathrm{~h}$ of light stimulation, compared to the following three control groups: Non-transfected CA1 pyramidal cells, cells expressing only the fluorescent protein citrine that were stimulated $\mathrm{O} / \mathrm{N}$ under the same conditions as Aion-expressing cells and Aion-expressing cells without $\mathrm{O} / \mathrm{N}$ stimulation. Black lines: mean values $\pm \mathrm{SEM}, \mathrm{n}_{\text {Non-transfected }}=6$ cells, $n_{\text {citrine-only }}=7$ cells, $n_{\text {Aion }}=7$ cells, $n_{\text {Aion }}$ No light $=6$ cells, one-way ANOVA, ${ }^{*} p<0.05$, n.s. $=$ not significant.

\section{Improving and restricting membrane expression of Aion to the somatodendritic compartment}

343 For the functional characterization of Aion in CA1 pyramidal neurons, we used a final plasmid concentration of $20 \mathrm{ng} / \mu \mathrm{l}$ for single-cell electroporation. This concentration led to robust, membrane-localized expression (Fig. 2Ai) and was well tolerated by the cells, leaving basic neuronal parameters intact (Fig. 4I). However, in some cases, opsin accumulations were visible at the soma, the basal dendrites and the proximal region of the main apical dendrite (Fig. S4A). Notably, despite these local accumulations, there was still significant membrane expression of Aion detectable throughout the cell (Fig. S4Ai). Nonetheless, to improve protein trafficking and to avoid local protein accumulations, we added the membrane trafficking signal (ts: KSRITSEGEYIPLDQIDINV) from the mammalian inward rectifying $\mathrm{K}^{+}$channel Kir2.1 between the coding sequences for Aion and citrine and the Kir2.1 endoplasmic reticulum export signal (ER: FCYENEV) at the C-terminus of citrine. Both modifications were previously shown to reduce intracellular aggregation of the ACR GtACR2 (Mahn et al., 2018) and the $\mathrm{Cl}^{-}$ pump NpHR (Gradinaru et al., 2010). The resulting construct, Aion-ts-citrine-ER, displayed enhanced membrane trafficking with no detectable intracellular accumulations (Fig. S4B). Moreover, Aion-ts-citrine-ER showed similar silencing capacity as the original Aion when electroporated at a fourfold lower concentration ( $5 \mathrm{vs} .20 \mathrm{ng} / \mu \mathrm{l}$ ), yielding a sustained rheobase shift of $404.5 \pm 111.3 \mathrm{pA}$ and efficient suppression of APs (82.6\%, range: $67.5-100 \%$ ) during the entire $47 \mathrm{~s}$ recording period after stimulation with a brief blue light pulse (Fig. S4C-F; see Fig. 3C-F for original Aion).

We used a second approach to improve membrane trafficking of Aion by attaching a C-terminal Kv2.1-trafficking sequence, which in addition of enhancing membrane localization, restricts expression to the somatodendritic compartment (Lim et al., 2000). Soma targeting has the 
366 added benefit of preventing expression of the ACR in axon terminals where functionality might 367 be limited due to an excitatory $\mathrm{E}_{\mathrm{Cl}}$ (Wright et al., 2011; Mahn et al., 2018). The soma-targeted 368 variant of Aion (somAion) showed enhanced membrane trafficking and was confined to the 369 soma and main apical dendrite (Fig. 5A, B). Despite local restriction of somAion its 370 photocurrent densities were slightly enhanced (peak: $1.5 \pm 0.3 \mathrm{pA} / \mathrm{pF}$; stationary: $0.4 \pm 0.1$

$371 \mathrm{pA} / \mathrm{pF}$ ) compared to those in neurons expressing the non-soma targeted Aion (peak: $1.3 \pm 0.3$ $372 \mathrm{pA} / \mathrm{pF}$; stationary: $0.3 \pm 0.1 \mathrm{pA} / \mathrm{pF}$ ) (Fig. $5 \mathrm{C}$ ). Furthermore, consistent with the efficient 373 membrane expression in the somatodendritic compartment, somAion yielded stronger 374 inhibition of AP firing than non-soma targeted Aion, shifting the rheobase to higher values and 375 leading to a complete and sustained block of current-evoked APs in most cells (4 out of 6 cells, 376 Fig. 5D-F, see Fig. 3C-F and S3D, E for comparison to non-soma targeted Aion versions). 377 Taken together, soma-targeting of Aion overcomes the suboptimal trafficking, while avoiding 378 expression in axon terminals, yielding a more effective tool for optogenetic inhibition at the cell 379 soma. 
A somAion: Aion citrine $\mathrm{Kv} 2.1$

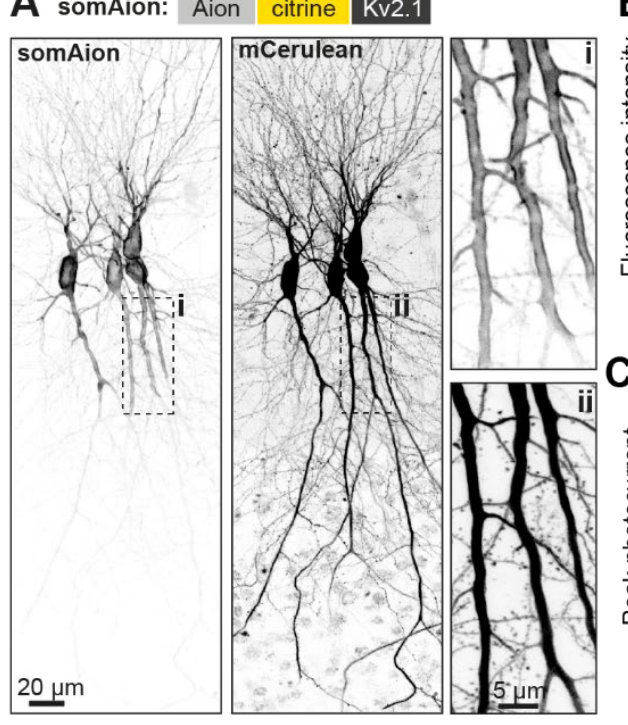

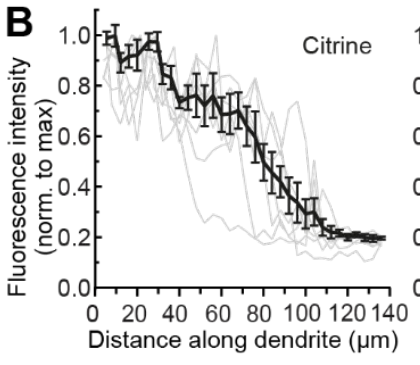
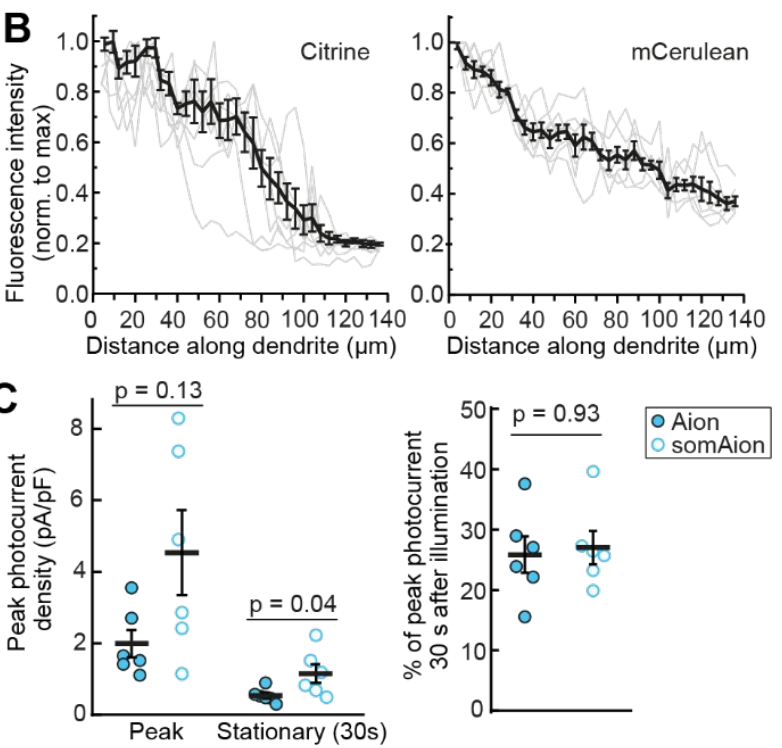

somAion: Silencing efficiency
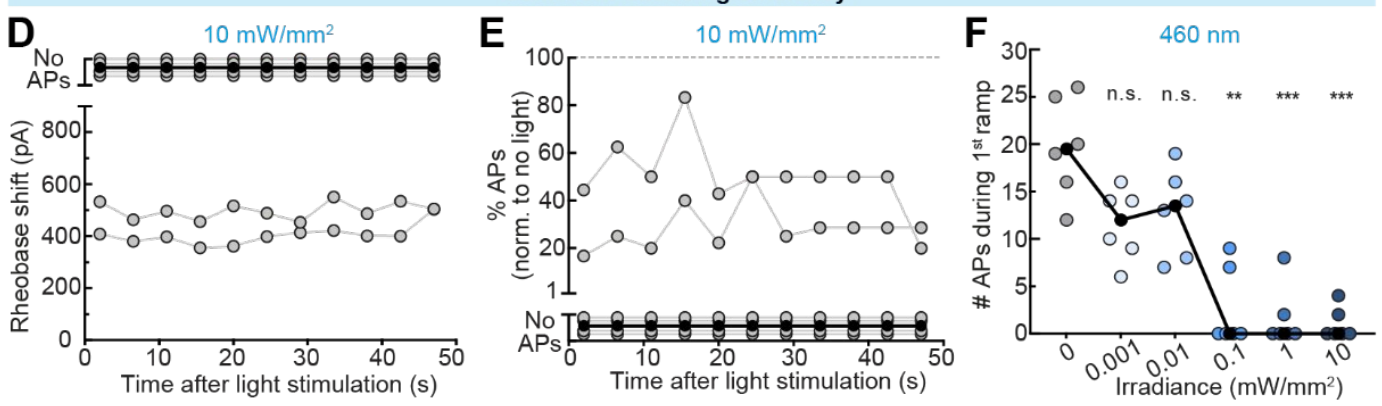

Figure 5. somAion is a soma-targeted variant of Aion with enhanced silencing capacity. (A) Maximum-intensity projection images of two-photon stacks showing expression of somAion in CA1 pyramidal neurons after single-cell electroporation in organotypic hippocampal slice cultures. Fluorescence intensity is shown as inverted gray values. Opsin-citrine fluorescence was localized at the plasma membrane and restricted to the somatodendritic compartment (left image, inset i). mCerulean serves as a morphology marker (right image, inset ii). (B) Quantification of citrine (left) and mCerulean (right) fluorescence along the main apical dendrite of somAion-expressing neurons ( $n=7$ cells). Grey lines correspond to measurements in individual cells, black lines indicate mean \pm SEM. (C) Left: comparison of Aion and somAion peak and stationary (30 s post light) photocurrent densities evoked by a short $460-\mathrm{nm}$ light pulse $\left(1 \mathrm{~s}, 10 \mathrm{~mW} / \mathrm{mm}^{2}\right)$. Right: quantification of stationary, peak-normalized photocurrent amplitude at $30 \mathrm{~s}$ after channel opening. Black lines indicate mean \pm SEM and circles represent measurement from single cells ( $n=6$ cells). Mann-Whitney test, exact $p$-values are shown. (D-F) Rheobase measurements as described previously. (D) Quantification of the rheobase shift and (E) the relative change in the number of current ramp-evoked APs during $47 \mathrm{~s}$ after light stimulation (460 $\mathrm{nm}, 1 \mathrm{~s}, 10 \mathrm{~mW} / \mathrm{mm}^{2}, \mathrm{n}=6$ cells). In most cells, activation of somAion led to complete AP block. (F) Number of APs evoked during the first current ramp after opening of somAion with $1 \mathrm{~s}$ blue light at indicated irradiances. Significant AP block was achieved at $0.1 \mathrm{~mW} / \mathrm{mm}^{2}(n=6$ cells). For (D-F) grey or blue circles represent single measurement data points and black circles correspond to medians, Friedman test, ${ }^{*} p<0.05,{ }^{* *} p<0.01,{ }^{* * *} p<0.001$, n.s. $=$ not significant.

\section{All-optical manipulation of a nociceptive circuit in Drosophila larvae}

To assess the functionality of Aion in vivo, we analyzed its ability to inhibit nociceptive circuit function in Drosophila larvae. We expressed Aion in a pair of major second order neurons (A08n) downstream of the primary nociceptors (C4da) covering the larval body wall (Fig. 6A, 
B). C4da and A08n neurons are part of a circuit sensing noxious mechanical stimuli, and their

405

406

407

408

409

410

411

412

413

414

415

416

417

418

419

420

421

422

423

424

425

426

427

428

429

430

431

432

433

434

435

436

437

438

439

440 activation elicits stereotyped rolling behavior (Zhong et al., 2010; Hu et al., 2017). After activation of Aion in A08n neurons with a blue light pulse, we observed a robust reduction in nociceptive touch responses, which could be completely reverted after orange light application to accelerate channel closure of Aion (Fig. 6B). The effect was comparable to A08n inactivation with other silencing tools, including the potent natural GtACR1 (Mohammad et al., 2017) upon acute green light exposure or chronic silencing with the inward rectifying potassium channel Kir2.1 (Fig. 6C, D). We next tested Aion-mediated silencing in an all-optical approach: we expressed CsChrimson specifically in the upstream C4da nociceptors and Aion in A08n neurons in the same larvae. CsChrimson-expressing C4da neurons were activated with red light before and after Aion activation, as well as after Aion inactivation. In this case we capitalized on the slow off-kinetics of Aion using 100x lower light intensity for its activation over a prolonged period of $30 \mathrm{~s}$ to avoid blue-light-mediated cross-activation of CsChrimson. This light protocol resulted in comparable inhibition of behavior as a shorter light pulse with higher intensity (Fig. 6E, F). In both cases, CsChrimson-induced nociceptive behavior was strongly reduced after Aion activation and could be largely recovered upon Aion inactivation with orange light (Fig. 6E). Without subsequent Aion inactivation, nociceptive behavior remained strongly reduced after 5 and $15 \mathrm{~min}$, and only partially recovered at $60 \mathrm{~min}$ after Aion-induced silencing of A08n neurons, demonstrating the long-lasting silencing capacity of this opsin (Fig. $6 \mathrm{~F})$.

We further generated transgenic flies with Aion variants optimized for expression (Aion-ts$\mathrm{mScarlet-ER)} \mathrm{and} \mathrm{somatodendritic} \mathrm{targeting} \mathrm{(somAion)} \mathrm{as} \mathrm{described} \mathrm{above} \mathrm{(see} \mathrm{Fig.} \mathrm{S4} \mathrm{and}$ Fig. 5) to investigate if these modifications might be beneficial for Aion functionality in Drosophila as well. We tested these Aion variants placed in transgene backbones for high or low expression (20xUAS or 5xUAS) in our all-optical paradigm as before (see Fig. 6E and Fig. S5A). All Aion variants were able to significantly inhibit nociceptive behavior after a low or high intensity blue light stimulus (Fig. S5B-D). However, Kv2.1 inclusion did not improve the potency of Aion - likely due to inefficiency of this signaling sequence in Drosophila. Moreover, high expression of the other trafficking-enhanced Aion constructs had detrimental effects on baseline behavior before A08n silencing. Nonetheless, as with CA1 pyramidal neurons, lower expression of trafficking-enhanced Aion was similarly sufficient to inhibit nociceptive behavior suggesting that tuning Aion levels might be beneficial to optimize behavioral experiments in different neuronal subtypes.

Overall, these results show that Aion can robustly and reversibly inhibit behavior by lightinduced silencing of specific neurons in vivo, as well as maintain light-independent silencing 

illumination.
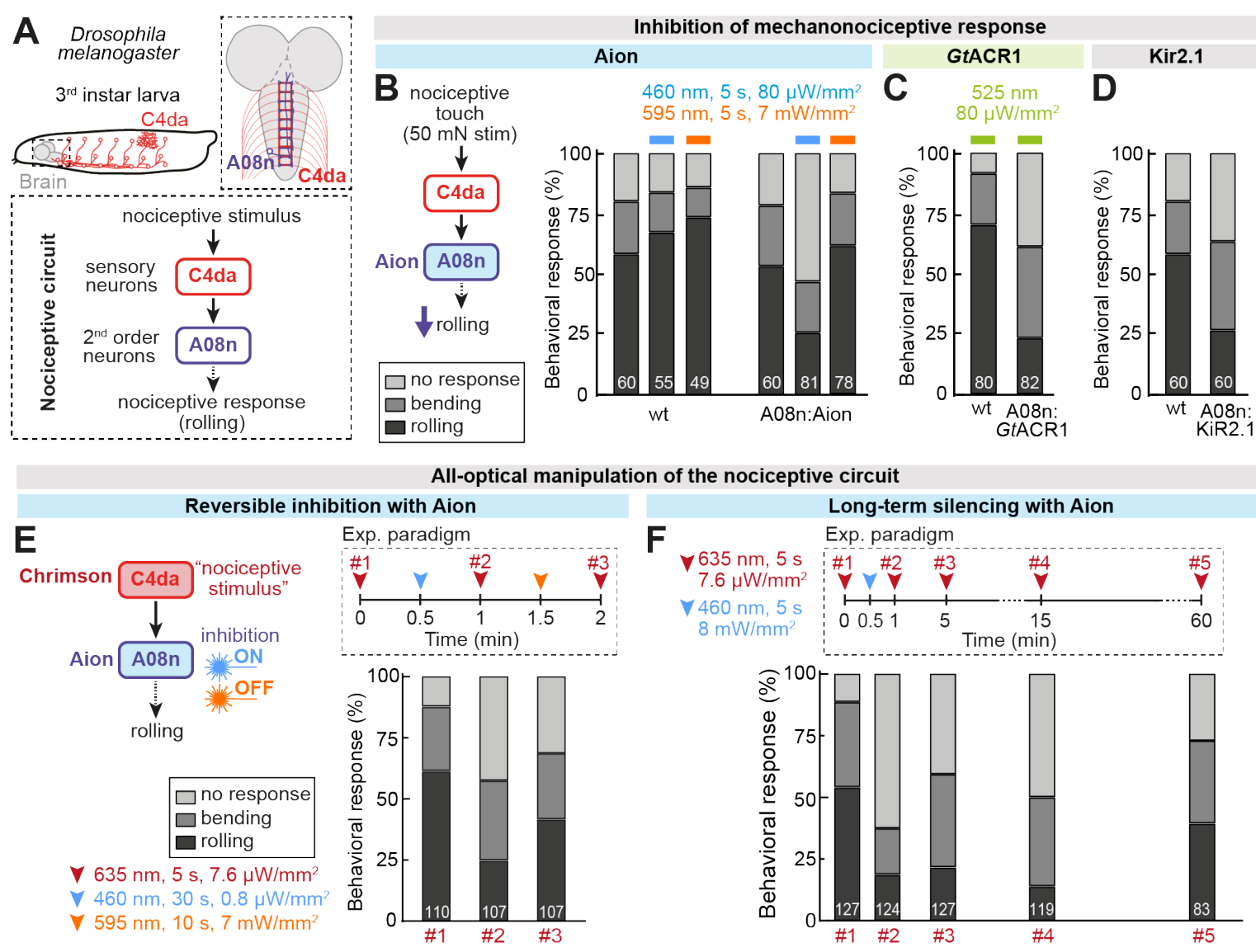

Figure 6. Aion enables inhibition of nociceptive circuit function in Drosophila melanogaster larvae over extended time periods. (A) Schematic model of nociceptive sensory neurons (C4da) and connected downstream neurons (A08n) in Drosophila larvae. (B) Nociceptive touch responses were strongly reduced after blue light in animals expressing Aion in A08n neurons, but not in controls (wt). The responses could be fully recovered after orange light exposure. (C) Larvae expressing GtACR1 in A08n neurons showed robustly reduced nociceptive responses under constant green light exposure. (D) Constitutive silencing by expression of Kir2.1 in A08n lead to similarly strong inhibition of larval nociception as with Aion. For (B-D) the behavioral response to a $50 \mathrm{mN}$ mechanical stimulus is shown. (E) All-optical paradigm for inhibition of A08n neurons with Aion and activation of C4da neurons with CsChrimson. Repeated induction of nociceptive behavior with red light was strongly inhibited after blue light-induced Aion activation and largely reversed by orange light. (F) Activation of Aion expressed in A08n neurons with a single blue light pulse $(5 \mathrm{~s})$ resulted in reduction of nociceptive responses for at least $15 \mathrm{~min}$ and partially recovered only after $60 \mathrm{~min}$. For (E-F) behavioral responses to CsChrimson activation in C4da neurons at the indicated time points are shown. Numbers of animals are indicated by white numbers in $(B-F)$.

\section{Discussion}

Here we sought to generate a potent, slow-cycling ACR with a temporally extended conducting state by combining the C128A mutation in Phobos ${ }^{\mathrm{CA}}$ (Wietek et al., 2017) with a number of D156 mutations. The amino acids C128 and D156 form the DC-gate and are crucial for the 
reprotonation of the Schiff base, which terminates the conducting state (Nack et al., 2010; Volkov et al., 2017). In CCRs these residues were systematically mutated to obtain stabilized, step-function opsins with open state time constants of up to 30 min (Yizhar et al., 2011; Gong et al., 2020). Mutagenesis at either of the two residues (C128, D156) was previously shown to also extend the conducting state of various engineered and natural ACRs (Berndt et al., 2014; Wietek et al., 2014; Sineshchekov et al., 2015; Berndt et al., 2016; Wietek et al., 2017; Govorunova et al., 2018). However, the channel-closing time constant of published slowcycling ACRs was so far not exceeding 5 min (Sineshchekov et al., 2015; Berndt et al., 2016; Wietek et al., 2017). Thus, we sought to combine mutations at both residues, while preserving channel functionality and anion selectivity. This effort led to Aion, a step-function ACR with enhanced potency and a channel-closing time constant of approx. 15 min (Fig. 7).

\section{Improved operational light sensitivity}

476 Due to its slow photocycle, Aion yields effective inhibition with short light pulses delivered 477 several minutes apart (Fig. 4) or with prolonged, low-irradiance illumination (Fig. 6E,F), thereby 478 reducing undesired side effects of high photon flux over long time periods in optogenetic 479 silencing experiments. These side effects include tissue heating, phototoxicity or disturbance 480 of the sensory system (perception of light) during behavioral experiments. Furthermore, since the slow photocycle enables accumulation of conducting (i.e. open) anion channels under low photon exposure over time, Aion is in principle also suitable for long-lasting silencing of deep brain regions where light penetrance is low. At the same time, this might pose a limitation in experiments, where spatially confined silencing is required, since Aion may get activated outside the target area under continuous illumination, even by low irradiances far away from the light source (Babl et al., 2019; Li et al., 2019).

Light-gated $\mathrm{K}^{+}$-channels with high light sensitivity and long-lasting action might pose a tractable alternative to ACRs. Activation of a $\mathrm{K}^{+}$conductance should lead to robust hyperpolarization and membrane shunting independently of the developmental state or the cellular compartment of the neuron. Recently, two-component silencing tools were reported that employ cyclic nucleotide-gated $\mathrm{K}^{+}$-channels in combination with blue light-activated nucleotide cyclases (Beck et al., 2018; Bernal Sierra et al., 2018). Indeed, potent silencing of neuronal activity was demonstrated with these tools, including silencing of neuronal activity in the mammalian brain in vivo. While providing a promising new direction for efficient, light-sensitive silencing, putative caveats are off-target effects due to light-induced elevation of cyclic nucleotides, dark-activity of the cyclases and background-activation of the cyclic nucleotide-gated $\mathrm{K}^{+}$-channels by endogenous cyclic nucleotides. Such side-effects may explain the unexpected alterations of hippocampal activity in mice expressing these tools (Kleis et al., 2022). The recently 
discovered natural $\mathrm{K}^{+}$channels (Govorunova et al., 2021) might provide a solution to such limitations, albeit selectivity of $\mathrm{K}^{+}$over $\mathrm{Na}^{+}$ions and protons in general still might need improvement for reliable neuronal applications.

Efficient optogenetic inhibition in deep brain areas was also achieved by using the red-lightactivated $\mathrm{Cl}^{-}$pump Jaws (Chuong et al., 2014). This study demonstrated inhibition of neurons in the mouse cortex over a range of 1-3 $\mathrm{mm}$ through the intact skull. However, as previously discussed, ion pumps present some limitations, such as actively changing the intracellular ionic composition, especially when prolonged inhibition periods are required (Raimondo et al., 2012; Mahn et al., 2016; Wiegert et al., 2017b). In this context, minimally invasive optogenetic inhibition with slow-cycling ACRs such as Aion could hold the advantage that ionic gradients are not actively changed, as they operate by shunting rather than hyperpolarization of the membrane voltage.

Another caveat of optogenetic silencers that require continuous illumination is the potential interference with behavior during in vivo experiments, which can ultimately lead to misinterpretations regarding the function of the neural circuit under investigation. Many animal species, including C. elegans or Drosophila larvae, detect and avoid short-wavelength light in the UV-blue spectrum even at low intensities (Xiang et al., 2010; Keene and Sprecher, 2012; Ghosh et al., 2021). This makes the implementation of optogenetic manipulations challenging in living animals, especially when illumination of the entire body is required. As shown previously for Phobos ${ }^{\mathrm{CA}}$, expressing Aion in Drosophila larvae (Wietek et al., 2017), we could temporally dissociate activation of the ACR from the behavioral manipulation (i.e. mechanical stimulus). Therefore, Aion allows temporal dissociation of functional silencing and the physiological responses evoked by the light stimulus directly.

\section{5 \\ Long dark interstimulus intervals \& combination with other optical tools}

526 Step-function ACRs further allow optogenetic silencing together with temporally precise optical

527 activation of a second population of neurons in vivo, despite some spectral overlap of both 528 opsins. Even the most red-shifted opsins show significant light absorbance in the blue range. 529 Therefore, combining a red-shifted excitatory opsin, such as Chrimson (Klapoetke et al., 2014), 530 with blue light-sensitive inhibitory opsins, is complicated by the putative blue light-activation of 531 Chrimson during activation of the silencing tool. One way to address this issue can be by 532 temporally dissociating the activation of the two opsins. Switching Aion to an open state with 533 blue light before the start of the manipulation of Chrimson-expressing neurons allows to 534 circumvent unintended optical cross-talk. Another way to avoid blue-light-mediated activation 535 of Chrimson during the activation of the ACR is to use prolonged, low-irradiance illumination. 
536 In this way, unintended activation of fast cycling opsins, such as Chrimson, is avoided, while

537 Aion accumulates in the conducting state over time. Thus, mutually exclusive activation of two

538 opsins is possible using a slow-cycling blue light-sensitive opsin and a fast-cycling red light-

539 sensitive opsin. The disadvantage of these approaches is the temporal dissociation or

540 imprecision, preventing optogenetic manipulations with exact ms-timing.

541

542 The long interstimulus intervals during Aion-mediated inhibition can in principle also simplify 543 optical monitoring of neuronal activity during the silencing period. Since illumination of the 544 opsin is required only transiently, imaging or photometry experiments could be performed in 545 the dark periods, thus avoiding light artefacts. However, several constraints need to be 546 considered, which limit such seemingly straightforward experiments. First, due to the high 547 operational light sensitivity of Aion and other slow-cycling ACRs, exposure to continuous 548 fluorescence excitation light will likely lead to activation of Aion, already at times when silencing 549 is not intended, such as during baseline recordings. This is especially problematic with green 550 fluorescent probes, which require excitation in the blue spectrum. Thus, ideally, red-shifted 551 indicators are used so as to avoid inadvertent activation of Aion. In addition to channel552 opening, accelerated channel closing with red-shifted light needs to be considered. In this 553 case, excitation in the green spectrum, typically used for red fluorescent indicators, might drive 554 channel closing over time. We previously characterized the action spectrum of Phobos ${ }^{\mathrm{CA}}$ 555 (Wietek et al., 2017), the parent ACR of Aion, showing that inactivation is most efficient 556 between 550 and $610 \mathrm{~nm}$, leaving only an imaging window compatible with far red-shifted 557 sensors, such as the calcium indicator NIR-GECO (Qian et al., 2020) or the QuasAr voltage 558 sensor family (Kralj et al., 2011; Adam et al., 2019).

\section{Trafficking-optimization and soma-targeting}

560 Aion showed efficient membrane localization and did not alter neuronal biophysical properties when expressed at moderate levels. However, in some cases local, intracellular aggregations of the opsin were observed, similar to other first-generation opsins, such as NpHR (Gradinaru 563 et al., 2010) and GtACR2 (Mahn et al., 2018). While expression levels and thus, overexpression artefacts can be well-controlled with single-cell electroporation, this is not trivial when using viral injections or transgenic lines. Thus, trafficking-optimization is required to avoid aggregation of Aion in intracellular organelles, potentially leading to cell stress and toxicity.

567 Insertion of the canonical sequences for ER export and membrane trafficking from Kir2.1 568 improved membrane expression of Aion, avoiding intracellular accumulations. Unlike previous 569 reports (Gradinaru et al., 2010; Mahn et al., 2018), we did not observe larger photocurrents or 570 stronger silencing in this trafficking-enhanced version of Aion. However, we observed similar 571 potency already at a fourfold lower DNA concentration, compared to the original Aion version. 
572 This indicates, that maximal membrane expression was reached in Aion, when aggregates

573 were observed and that the same levels of membrane expression could be reached with less

574 DNA and without aggregates using the trafficking-enhanced version.

575

576 While efficient membrane expression is desired in the somatodendritic compartment, axonal 577 localization of ACRs should be avoided. In some axons and synaptic terminals, elevated $\mathrm{Cl}^{-}$ 578 concentrations are reported (Turecek and Trussell, 2001; Szabadics et al., 2006; Pugh and 579 Jahr, 2011), thus potentially leading to depolarization upon activation of ACRs. Indeed, local 580 activation of GtACR2 at axon terminals led to presynaptic neurotransmitter release (Mahn et 581 al., 2016; Messier et al., 2018) and antidromic spiking (Malyshev et al., 2017; Mahn et al., 582 2018). Soma-targeting of GtACR2 avoided axonal expression and enhanced membrane 583 expression in the somatodendritic compartment (Mahn et al., 2018; Messier et al., 2018). We 584 therefore applied a similar strategy to generate the soma-targeted Aion variant somAion. 585 Indeed, C-terminal attachment of the soma-targeting signal from Kv2.1 (Lim et al., 2000) led 586 to restricted expression of somAion in the soma and proximal dendrites of CA1 pyramidal 587 neurons. Moreover, as reported previously, this modification enhanced the silencing capacity 588 of somAion compared to the original Aion or the trafficking-optimized Aion. This is likely due to 589 the high-density expression of somAion in the somatodendritic compartment, efficiently 590 shunting depolarization close to the axon initial segment and thus efficiently blocking AP 591 generation.

592

593 Although soma-targeting of ACRs efficiently restricts their expression to the somatodendritic 594 compartment, thereby overcoming the issue of axonal excitation and antidromic spiking, it 595 limits the application of ACRs to somatic inhibition. If silencing AP initiation is the main goal, 596 soma-targeted ACRs may be the tools of choice. However, if silencing of dendritic inputs 597 anywhere in the cell is required, a non-soma targeted, trafficking-optimized ACR is preferable. 598 Moreover, ACR-mediated somatic inhibition does not allow local silencing of presynaptic 599 terminals, which is required to investigate the role of specific projections from one neuronal 600 population to its target region. In this case, alternative silencing methods should be considered. 601 Inspired by potent inhibition via $G_{i / o}$ signaling of G-protein coupled receptors (GPCRs), such 602 as $\mathrm{GABA}_{B}$ receptors or the chemogenetic silencing tool hM4Di (Armbruster et al., 2007; 603 Stachniak et al., 2014), Gi/o-coupled rhodopsin GPCRs were recently demonstrated as potent 604 tools for presynaptic silencing. These include eOPN3, a mosquito-derived homolog of the 605 mammalian encephalopsin (Mahn et al., 2021) and a lamprey parapinopsin (PPO) (Copits et 606 al., 2021). 


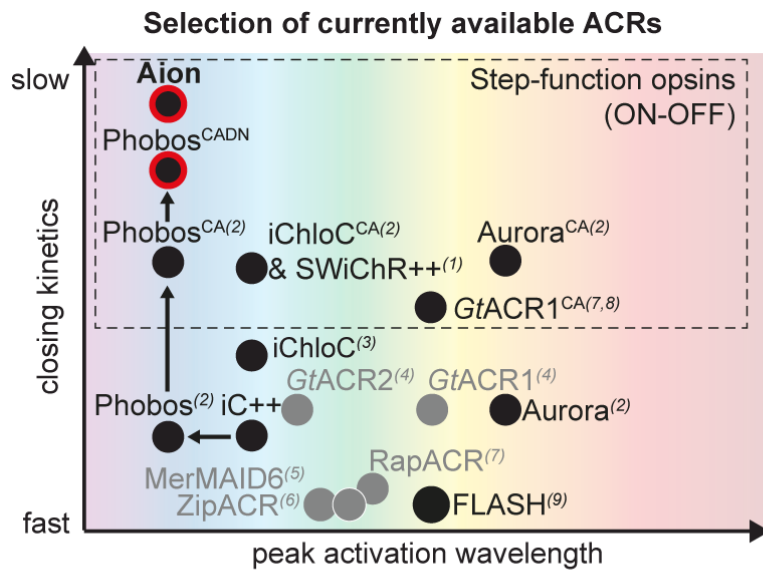

Engineered ACRs $O$ Newly generated step-function ACRs Natural ACRs $\leftarrow$ Aion engineering strategy

Figure 7. Aion broadens the available toolkit of optogenetic silencers in the temporal domain. Schematic diagram showing a selection of the currently available ACRs used as optogenetic silencers in neurons. The ACRs are sorted according to their approximate peak activation wavelength ( $x$ axis) and closing kinetics ( $y$ axis). Engineered and natural ACRs are depicted as black and grey circles, respectively. Phobos ${ }^{\text {CADN }}$ and Aion, the slowcycling ACRs developed in this study, are highlighted with a red outline and the engineering strategy is indicated by black arrows. References to the published ACRs are indicated by numerical superscripts: 1 (Berndt et al., 2016), 2 (Wietek et al., 2017), 3 (Wietek et al., 2015), 4 (Govorunova et al., 2015), 5 (Oppermann et al., 2019), 6 (Govorunova et al., 2017), 7 (Govorunova et al., 2018), 8 (Sineshchekov et al., 2016), 9 (Kato et al., 2018), 10 (Govorunova et al., 2020)

\section{Engineered vs natural slow-cycling ACRs}

We systematically compared the performance of Aion to GtACR1 ${ }^{\mathrm{CA}}$, a slow-cycling variant engineered from the naturally-occurring GtACR1 by introduction of the point mutation C102A (Sineshchekov et al., 2015; Govorunova et al., 2018), which is homologous to the mutation C128A in Aion. However, in contrast to Aion, where the C128A mutation not only slows down channel closing kinetics, but also enables accelerated channel closure upon illumination with

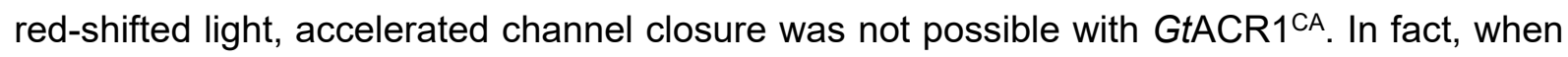
red light was delivered at a time point when GtACR $1^{\text {CA }}$-mediated photocurrents had almost decayed back to baseline (e.g. $198 \mathrm{~s}$ after initial opening), an increase in $\mathrm{Cl}^{-}$conductance was observed, suggesting that red light brings GtACR $1^{\mathrm{CA}}$ to an intermediate conducting state in the photocycle rather than to the ground state. Hence, GtACR $1^{\mathrm{CA}}$ exhibits slow-cycling but not truly step-function properties, hindering its applicability for neuronal inhibition with precisely timed on and offset.

The second point mutation that confers Aion its long-lasting open state is on the residue D156 of the DC-gate. However, this residue is not conserved in natural ACRs, and most frequently replaced by a serine (S130) (Sineshchekov et al., 2015; Kim et al., 2018). Mutation of the corresponding S130 to alanine in GtACR1 did not show a strong effect on the off-kinetics 645 (Sineshchekov et al., 2015). The different role of key residues in natural ACRs compared to 646 CCR-derived engineered ACRs emphasizes the differences in photocycle and gating 647 mechanisms. Certainly, structure-function insights derived from crystallography studies, such 
648 as the work by H. Kato, Y. Kim and colleagues who resolved the crystal structures of iC++ and

649 GtACR1, are key to determine which properties and mutations are transferable between 650 engineered and natural ACRs (Kato et al., 2018; Kim et al., 2018). Using structure-guided 651 approaches to combine the high single-channel conductance of the natural cryptophyte 652 GtACRs with the step-function properties of CCR-derived ACRs hopefully leads the way to 653 new, more potent step-function ACRs.

\section{Materials and Methods}

\section{Molecular cloning of ACR variants}

656 For HEK-cell expression, mutations were introduced in previously described ACR constructs 657 of GtACR1 (Wietek et al., 2016) (Addgene \#85464) and Phobos ${ }^{\mathrm{CA}}$ (Wietek et al., 2017) 658 (Addgene \#98169) using the QuikChange II kit (Agilent Technologies, Santa Clara, CA). 659 Successful single point mutagenesis was verified by conventional Sanger sequencing.

660

661 For neuronal expression, all engineered ACRs (see Table 1 for details) were cloned into an 662 AAV2-backbone behind a human synapsin (hSyn) promoter, followed by the sequence for a 663 citrine fluorescent protein. Phobos ${ }^{\mathrm{CA}}$ mutants (D156C/Aion, D156N, D156S, D156H) were 664 generated by site-directed mutagenesis of our previously reported plasmid Phobos ${ }^{\mathrm{CA}}$-citrine 665 (Wietek et al., 2017) (Addgene \#98218). The membrane-trafficking optimized variant of Aion, 666 namely Aion-ts-citrine-ER was generated by adding a trafficking signal (ts: 667 KSRITSEGEYIPLDQIDINV) from the Kir2.1 channel between the Aion and the citrine coding 668 sequences, and the Kir2.1 ER export signal (FCYENV) following the C-terminus of citrine 669 (pAAV-hSyn-Aion-ts-citrine-ER). The soma-targeted variant, somAion, was generated by 670 fusing a trafficking signal from the potassium channel Kv2.1 (Lim et al., 2000) to the C-terminus 671 of Aion-citrine (pAAV-hSyn-Aion-citrine-Kv2.1). 


\begin{tabular}{|l|l|}
\hline DNA Construct & Concentration $(\mathrm{ng} / \mathrm{\mu l})$ \\
\hline hSyn-Phobos ${ }^{\text {CADC}}$-citrine (Aion) & 20 \\
\hline hSyn-Aion-citrine-Kv2.1 (somAion) & 20 \\
\hline hSyn-Aion-ts-citrine-ER & 5 \\
\hline hSyn-Phobos $^{\text {CADN_citrine }}$ & 20 \\
\hline hSyn-Phobos ${ }^{\text {CADS_citrine }}$ & 20 \\
\hline hSyn-Phobos ${ }^{\text {CADH_citrine }}$ & 20 \\
\hline hSyn-GtACR1 ${ }^{\text {CA-citrine }}$ & 5 \\
\hline hSyn-mCerulean & 50 \\
\hline hSyn-citrine & 20 \\
\hline
\end{tabular}

674 Table 1. List of DNA constructs used for experiments in organotypic hippocampal slices. Plasmids were 675 used for single-cell electroporation of CA1 neurons at the indicated concentrations.

\section{Patch-Clamp experiments in HEK293 cells}

677 HEK293 culture (ECACC 85120602, Sigma-Aldrich, Munich, Germany), transfection and electrophysiological recordings were performed as described previously (Grimm et al., 2017;

679 Oppermann et al., 2019). In detail, cells were seeded at a density of $10^{5} / \mathrm{ml}$ on poly-D-lysine680 coated coverslips, supplemented with $1 \mu \mathrm{M}$ all-trans retinal, were transiently transfected using 681 Fugene HD (Promega, Madison, WI) one day post seeding. 24 - 48 days post-transfection, 682 whole-cell patch-clamp recordings were performed at $22^{\circ} \mathrm{C}$ using fire-polished patch pipettes 683 (1.5 - $2.5 \mathrm{M} \Omega$ pipette resistance), and a $140 \mathrm{mM} \mathrm{NaCl}$ agar bridge reference electrode. Patch 684 pipettes were filled with (in $\mathrm{mM}$ ): $2 \mathrm{MgCl}_{2}, 2 \mathrm{CaCl}_{2}, 1 \mathrm{KCl}, 1 \mathrm{CsCl}, 10 \mathrm{EGTA}, 10 \mathrm{HEPES}, 110$ $685 \mathrm{Na}$-Aspartate, while the bath solution contained: $2 \mathrm{MgCl}_{2}, 2 \mathrm{CaCl}_{2}, 1 \mathrm{KCl}, 1 \mathrm{CsCl}, 10 \mathrm{HEPES}$, $686140 \mathrm{NaCl}$, both pH 7.2 adjusted with N-methyl-D-glucamine or citric acid. The buffer osmolarity 687 was set with glucose to 320 mOsm (extracellular) or 290 mOsm (intracellular). Cells were 688 measured at $0 \mathrm{mV}$ membrane potential, corrected for a liquid junction potential of $-10.5 \mathrm{mV}$. 689 Only cells with an access resistance below $10 \mathrm{M} \Omega$ and at least 30-fold higher membrane 690 resistance where measured. Signals were amplified (AxoPatch200B), digitized 691 (DigiData1440A), and acquired using Clampex 10.4 (Molecular Devices, Sunnyvale, CA). Light 692 from a Polychrome V (TILL Photonics, Planegg, Germany) with $7 \mathrm{~nm}$ bandwidth guided into 693 an Axiovert 100 microscope (Carl Zeiss, Jena, Germany) controlled via a programmable 694 shutter system (VS25 and VCM-D1; Vincent Associates, Rochester, NY). Irradiances were 695 measured in the sample plane using a calibrated photodiode power sensor (S130VC, 
Thorlabs, Bergkirchen, Germany) after passing through a W Plan-Apochromat 40×/1.0 DIC objective (0.066 $\mathrm{mm}^{2}$ illuminated field, Carl Zeiss).

\section{Preparation of organotypic hippocampal slice cultures and transgene delivery}

699 Organotypic hippocampal slices were prepared from Wistar rats at post-natal day 5-7 as

700

701

702

703

704

705

706

707

708

709

710

711

712

713

714

715

716

717

718

719

720

721

722

723

724

725

726

727

728

729 previously described (Gee et al., 2017). Briefly, dissected hippocampi were cut into $350 \mu \mathrm{m}$ slices with a tissue chopper (Mcllwain type 10180, Ted Pella) and placed on a porous membrane (Millicell $\mathrm{CM}$, Millipore). Cultures were maintained at $37^{\circ} \mathrm{C}, 5 \% \mathrm{CO} 2$ in a medium containing 80\% MEM (Sigma M7278), 20\% heat-inactivated horse serum (Sigma H1138) supplemented with $1 \mathrm{mM}$ L-glutamine, $0.00125 \%$ ascorbic acid, $0.01 \mathrm{mg} / \mathrm{ml}$ insulin, $1.44 \mathrm{mM}$ $\mathrm{CaCl}_{2}, 2 \mathrm{mM} \mathrm{MgSO}_{4}$ and $13 \mathrm{mM}$ D-glucose. Slice cultures were allowed to mature for at least 2 weeks in the incubator before experimental assessment. No antibiotics were added to the culture medium. Pre-warmed medium was replaced twice per week.

For transgene delivery in organotypic slices, individual CA1 pyramidal cells were transfected by single-cell electroporation between DIV 14-16 as previously described (Wiegert et al., 2017a). Except for pAAV-hSyn-GtACR1-C102A and pAAV-hSyn-Aion-ts-citrine-ER, which were used at a final concentration of $5 \mathrm{ng} / \mu \mathrm{l}$, all other plasmids (see Table 1 for details) were used at a final concentration of $20 \mathrm{ng} / \mathrm{\mu l}$ in K-gluconate-based solution consisting of (in $\mathrm{mM}$ ): 135 K-gluconate, 10 HEPES, $4 \mathrm{Na}_{2}$-ATP, $0.4 \mathrm{Na}$-GTP, $4 \mathrm{MgCl}_{2}, 3$ ascorbate, $10 \mathrm{Na}_{2}-$ phosphocreatine ( $\mathrm{pH}$ 7.2). A plasmid encoding $\mathrm{pCl}-\mathrm{hSyn}-\mathrm{mCe}$ Culean (at $50 \mathrm{ng} / \mu \mathrm{l}$ ) was coelectroporated with the opsin plasmids and served as a morphology marker. Once the pipette containing the plasmid mix was touching the membrane of the target cell, an Axoporator $800 \mathrm{~A}$ (Molecular Devices) was used to deliver 50 hyperpolarizing pulses $(-12 \mathrm{~V}, 0.5 \mathrm{~ms})$ at $50 \mathrm{~Hz}$. During electroporation slices were maintained in pre-warmed $\left(37^{\circ} \mathrm{C}\right) \mathrm{HEPES}$-buffered solution (in mM): $145 \mathrm{NaCl}, 10 \mathrm{HEPES}, 25 \mathrm{D}$-glucose, $2.5 \mathrm{KCl}, 1 \mathrm{MgCl}_{2}$ and $2 \mathrm{CaCl}_{2}(\mathrm{pH} 7.4$, sterile filtered).

\section{Two-photon imaging of neurons in slice cultures}

Neurons in organotypic slice cultures (DIV 19-21) were imaged with two-photon microscopy to check for the live expression and subcellular localization of the different ACRs. The custombuilt two-photon imaging setup was based on an Olympus BX-51WI upright microscope upgraded with a multiphoton imaging package (DF-Scope, Sutter Instrument), and controlled by Scanlmage 2017b software (Vidrio Technologies). Fluorescence was detected through the objectives (Leica HC FLUOTAR L 25x/0.95 W VISIR or LUMPLFLN 60XW, Olympus) and the oil immersion condenser (NA 1.4) by two pairs of GaAsP photomultiplier tubes (Hamamatsu, 
H11706-40). Dichroic mirrors (560 DXCR, Chroma Technology) and emission filters (ET525/70m-2P, ET605/70m-2P, Chroma Technology) were used to separate green and red fluorescence. Excitation light was blocked by short-pass filters (ET700SP-2P, Chroma Technology). A tunable Ti:Sapphire laser (Chameleon Vision-S, Coherent) was set to $810 \mathrm{~nm}$ to excite mCerulean. An Ytterbium-doped 1070-nm pulsed fiber laser (Fidelity-2, Coherent) was used at $1070 \mathrm{~nm}$ to excite citrine, which was detected in the green channel. The opensource software Fiji (Schindelin et al., 2012) was used for visualization and processing of images.

\section{Electrophysiology of neurons in slice cultures}

At DIV 19-21, whole-cell patch-clamp recordings of opsin-transfected or wt CA1 pyramidal neurons were performed. Experiments were done at room temperature $\left(21-23^{\circ} \mathrm{C}\right)$ under visual guidance using a BX 51WI microscope (Olympus) equipped with Dodt-gradient contrast and a Double IPA integrated patch amplifier controlled with SutterPatch software (Sutter Instrument). Patch pipettes with a tip resistance of 3-4 $\mathrm{M} \Omega$ were filled with intracellular solution consisting of (in mM): $135 \mathrm{~K}$-gluconate, $4 \mathrm{MgCl}_{2}, 4 \mathrm{Na}_{2}$-ATP, $0.4 \mathrm{Na}$-GTP, $10 \mathrm{Na}_{2}$-phosphocreatine, 3 ascorbate, $0.2 \mathrm{EGTA}$, and $10 \mathrm{HEPES}$ (pH 7.2). Artificial cerebrospinal fluid (ACSF) was used as extracellular solution in the recording chamber and consisted of (in $\mathrm{mM}$ ): $135 \mathrm{NaCl}, 2.5 \mathrm{KCl}$, $2 \mathrm{CaCl}_{2}, 1 \mathrm{MgCl}_{2}, 10 \mathrm{Na}$-HEPES, 12.5 D-glucose, $1.25 \mathrm{NaH}_{2} \mathrm{PO}_{4}$ (pH 7.4). In all experiments synaptic transmission was blocked by adding $10 \mu \mathrm{M}$ CPPene, $10 \mu \mathrm{M} N B Q X$, and $100 \mu \mathrm{M}$ picrotoxin (Tocris) to the recording solution. Measurements were corrected for a liquid junction potential of $-14.5 \mathrm{mV}$. Access resistance of the recorded neurons was continuously monitored and recordings above $30 \mathrm{M} \Omega$ were discarded. A 16 channel LED light engine (CoolLED pE4000) was used for epifluorescence excitation and delivery of light pulses for optogenetic stimulation (ranging from 385 to $635 \mathrm{~nm}$ ). Irradiance was measured in the object plane with a 1918 R power meter equipped with a calibrated 818 ST2 UV/D detector (Newport, Irvine CA) and divided by the illuminated field of the Olympus LUMPLFLN 60XW objective $\left(0.134 \mathrm{~mm}^{2}\right)$.

For photocurrent density measurements in voltage-clamp mode CA1 cells expressing 758 Phobos ${ }^{\text {CADN }}$, Aion or GtACR1 ${ }^{\text {CA }}$ were held at $-35 \mathrm{mV}$ to detect outward $\mathrm{Cl}^{-}$currents elicited by 759 blue $\left(460 \mathrm{~nm}, 20 \mathrm{~ms}, 10 \mathrm{~mW} / \mathrm{mm}^{2}\right)$ or green light $\left(525 \mathrm{~nm}, 20 \mathrm{~ms}, 10 \mathrm{~mW} / \mathrm{mm}^{2}\right)$, and terminated 760 by orange $\left(595 \mathrm{~nm}, 1 \mathrm{~s}, 10 \mathrm{~mW} / \mathrm{mm}^{2}\right)$ or red light $\left(660 \mathrm{~nm}, 1 \mathrm{~s}, 10 \mathrm{~mW} / \mathrm{mm}^{2}\right)$, respectively. To calculate photocurrent densities, the peak and stationary (at 30 and $120 \mathrm{~s}$ after light offset) photocurrent amplitudes (in pA) were divided by the cell membrane capacitance (in pF) which was automatically recorded by the SutterPatch software in voltage-clamp mode $\left(V_{\text {hold }}=-75\right.$ $\mathrm{mV})$. 
In current-clamp experiments holding current was injected to maintain CA1 cells near their resting membrane potential ( -75 to $-80 \mathrm{mV})$. To assess the capability of Phobos ${ }^{\text {CADN }}$, Aion and GtACR $1^{\text {CA }}$ to block AP firing, a light pulse at their respective peak activation wavelength (460 or $525 \mathrm{~nm}, 20 \mathrm{~ms}, 10 \mathrm{~mW} / \mathrm{mm}^{2}$ ) was delivered after $5 \mathrm{~s}$ during a train of somatic current step injections (300 pA, $2 \mathrm{~s}, 2.5 \mathrm{~s} \mathrm{ISI}$, for $1 \mathrm{~min}$ ). To assess accelerated termination of silencing for each ACR, a light pulse at their respective peak inactivation wavelength (595 or $660 \mathrm{~nm}, 1 \mathrm{~s}$, $10 \mathrm{~mW} / \mathrm{mm}^{2}$ ) was delivered after $35 \mathrm{~s}$. Spiking rate was calculated before opening (0-5 s), after opening ( 5 - $45 \mathrm{~s}$ ) and after closing (45 - $55 \mathrm{~s}$ ) of the ACR by dividing the number of currentevoked APs by the respective time interval.

To measure the ability of Phobos ${ }^{\mathrm{CADN}}$, Aion, Aion-ts-citrine-ER and somAion to shift the rheobase upon light-activation, 13 depolarizing current ramps $(2 \mathrm{~s}$, from 0-600 pA up to 0-1000 pA, $2.5 \mathrm{~s} \mathrm{ISI)} \mathrm{were} \mathrm{injected} \mathrm{into} \mathrm{CA1} \mathrm{neurons} \mathrm{over} 1$ minute in dark and light conditions (1 s light pulse of $460 \mathrm{~nm}$ between $1^{\text {st }}$ and $2^{\text {nd }}$ current ramp injections) at irradiance values ranging from 0.001 to $10 \mathrm{~mW} / \mathrm{mm}^{2}$. For each ramp, the injected current at the time of the first AP was defined as the rheobase. The rheobase shift over time was calculated by subtracting the rheobase of each ramp after light stimulation from the rheobase value before light stimulation ( $1^{\text {st }}$ ramp). The relative change in the number of ramp-evoked APs was calculated counting the total number of APs elicited during each current ramp injection after light stimulation and normalized to the number of APs elicited at the same time point in the absence of light. The same experiment was conducted for GtACR $1^{\mathrm{CA}}$, but using $525 \mathrm{~nm}$ light.

For Aion and GtACR $1^{\mathrm{CA}}$ the ability to block AP firing was further quantified over a period of 5 minutes. For this, the change in membrane depolarization (after median filtering of the raw voltage traces) during somatic current step injections was measured before and after a brief light stimulus (1 s, $10 \mathrm{~mW} / \mathrm{mm}^{2}$, Aion: $460 \mathrm{~nm}$, GtACR1CA: $525 \mathrm{~nm}$ ). In long-term silencing experiments inside the incubator, $35 \mathrm{~mm}$ diameter petri dishes containing a Millipore membrane with two organotypic slices on top of $1 \mathrm{ml}$ of cell culture medium were placed on a custom-made LED chamber controlled by an Arduino board. Aion-mediated inhibition of depolarization-induced APs was evaluated after overnight (12 h) blue-light stimulation of Aionexpressing cells ( $3 \mathrm{~s} 460-\mathrm{nm}$ light pulses every $5 \mathrm{~min}, 0.3 \mathrm{~mW} / \mathrm{mm}^{2}$ ).

Passive and active membrane parameters were measured after $\mathrm{O} / \mathrm{N}$ blue light stimulation in 799 Aion-citrine-, citrine-only-expressing and non-transduced wt CA1 pyramidal cells. As an 800 additional control, the same measurements were done in Aion-citrine-expressing cells which 801 were not stimulated with light. Resting membrane potential, membrane resistance and 802 capacitance were automatically recorded by the SutterPatch software in voltage-clamp mode 
$803\left(\mathrm{~V}_{\text {hold }}=-75 \mathrm{mV}\right)$ in response to a voltage test pulse of $100 \mathrm{~ms}$ and $-5 \mathrm{mV}$. The number of elicited

804 APs were counted in response to a somatic current injection of $300 \mathrm{pA}$ in current-clamp mode

805 (0 pA holding current). For the $1^{\text {st }}$ elicited AP, the voltage threshold, peak and amplitude were 806 measured.

\section{Drosophila maintenance and generation of transgenes}

808 All fly stocks were maintained at $25^{\circ} \mathrm{C}$ and $70 \%$ rel. humidity on standard cornmeal $/$ molasses 809 food. All Drosophila stocks were obtained from the Bloomington Drosophila Stock Center 810 unless indicated otherwise (BDSC, Bloomington, Indiana, USA). The following lines were used: 811 A08n-splitGal4, 82E12-Gal4 (2nd chr.), UAS-Kir2.1 (Hu et al., 2017), 27H06-LexA (BDSC 812 \#54751), LexAop-CsChrimson (BDSC \#55139), UAS-GtACR1 (BDSC \#92983). Aion 813 constructs (Aion-cerulean, Aion-ts-scarlet-ER, somAion-citrine) were cloned into Drosophila 814 transgenic vectors (pUAST-AttB with 5xUAS, pJFRC7 with 20xUAS) and inserted into the 815 attP2 landing site by phiC31-mediated trangenesis (Groth et al., 2004) (BestGene, USA).

\section{Optogenetic behavioral assays}

817 Larvae expressing CsChrimson in C4da and Aion in A08n neurons (82E12-Gal4, 27H06818 LexA/+; UAS-CsChrimson/UAS-Aion) were grown in darkness on grape agar plates with yeast 819 paste containing $5 \mathrm{mM}$ all-trans-retinal (Sigma-Aldrich). Staged third instar larvae (96 $\mathrm{h} \pm 3 \mathrm{~h}$ $820 \mathrm{AEL}$ ) were carefully transferred under low red-light conditions to a $2 \%$ agar plates with a $1 \mathrm{ml}$ 821 water film. CsChrimson was activated with $635 \mathrm{~nm}$ light $\left(760 \mu \mathrm{W} / \mathrm{cm}^{2}\right)$ for $5 \mathrm{~s}$. Aion was 822 activated with $460 \mathrm{~nm}$ and intensities of $0.08-8 \mathrm{~mW} / \mathrm{cm}^{2}$ for up to $30 \mathrm{~s}$ and inactivated with 595 $823 \mathrm{~nm}$ at $7 \mathrm{~mW} / \mathrm{cm}^{2}$. Between each activation steps, $30 \mathrm{~s}$ of no light were included, to allow full 824 functional recovery of CsChrimson. Videos were taken during the experiment and analyzed 825 using the Fiji cell counter plugin (ImageJ, NIH, Bethesda). Staging, experiments, and analyses 826 were done in a blinded fashion. Rolling was defined as at least one complete $360^{\circ}$ roll. Bending 827 was defined as a c-shape like twitching, typically seen before rolling behavior. Turning behavior 828 describes head turning and thereby a direction changes of locomotion. Stop behavior 829 describes a stopping of movement, no change in behavior means no change in behavior. Stop 830 and turn, stop and no change in behavior were defined as non-nociceptive behavior. All 831 behavioral assays and analyses were performed in a blinded and randomized fashion.

\section{Mechanonociception assays}

833 Mechanonociception experiments were performed with calibrated von-Frey-filaments (50 $\mathrm{mN}$ ) 834 and staged third instar larvae (96h AEL $\pm 3 \mathrm{~h}$ ) expressing Aion, GtACR1 or Kir2.1 in A08n 835 neurons (A08n-splitGal4/UAS-Aion or UAS-GtACR1 or UAS-Kir2.1). Larvae were carefully 
transferred to a $2 \%$ agar plates with a $1 \mathrm{ml}$ water film and stimulated twice on mid-abdominal segments (a3-a6) within $2 \mathrm{~s}$. Behavioral responses (non-nociceptive (no response, stop, stop and turn), bending, rolling) were noted and only behavioral responses to the second stimulus were analyzed and plotted. Staging and experiments were done in a blinded fashion and randomized fashion.

\section{Statistics}

Statistical analyses were performed using GraphPad Prism 9.0. Not normally distributed data were tested for significant differences $\left({ }^{*} p<0.05,{ }^{* *} p<0.01,{ }^{* *} p<0.001\right)$ using either the nonparametric Mann-Whitney test (two groups, non-matching values), the Friedman (more than two groups, matching-values), or the Kruskal-Wallis test (more than two groups, nonmatching values) followed by Dunn's multiple comparisons test, as indicated in the figure legends. For HEK cell and neuronal recordings individual datapoints are shown together with the mean \pm standard error of the mean (SEM), or median, as indicated. Given $n$ numbers represent biological replicates (i.e. HEK-cells, neurons, Drosophila larvae). For behavioral analysis of Drosophila larvae chi-square test was performed.

\section{Acknowledgements}

We thank Meike Petersen, Maila Reh and Tharsana Tharmalingam for excellent technical support. Oren Princz-Lebel and Alberto J. González Hernández helped with initial characterization of Phobos ${ }^{\mathrm{CADC}}$ at the 2019 Cajal Course "Biosensors and Actuators in Cellular and Systems Neuroscience" and suggested the name "Aion". This work was funded by the German Research Foundation (SPP 1926, Project Nr.: 315380903 to J.S.W. and P.S., SFB 1078 B2 to P.H.). P.H. is a Hertie Senior Professor for Neuroscience supported by the Hertie Foundation.

\section{Author contributions}

Conceptualization: S.R.R., J.W., P.S., J.S.W.; Data Acquisition: S.R.R., J.W., F.T.; Analysis: S.R.R., J.W., F.T.; Methodology: S.R.R., J.W., F.T., K.S., P.S., J.S.W.; Supervision: P.H., P.S., J.S.W.; Funding Acquisition: P.H., P.S., J.S.W.; Project Administration: J. S.W.; Writing: S.R.R., J.S.W. with help from all other authors.

\section{Competing interests}

The authors declare no competing interests. 


\section{References}

Adam $Y$ et al. (2019) Voltage imaging and optogenetics reveal behaviour-dependent changes in hippocampal dynamics. Nature 569:413-417.

Armbruster BN, Li X, Pausch MH, Herlitze S, Roth BL (2007) Evolving the lock to fit the key to create a family of $G$ protein-coupled receptors potently activated by an inert ligand. Proc Natl Acad Sci U S A 104:5163-5168.

Babl SS, Rummell BP, Sigurdsson T (2019) The Spatial Extent of Optogenetic Silencing in Transgenic Mice Expressing Channelrhodopsin in Inhibitory Interneurons. Cell reports 29:1381-1395 e1384.

Beck S, Yu-Strzelczyk J, Pauls D, Constantin OM, Gee CE, Ehmann N, Kittel RJ, Nagel G, Gao S (2018) Synthetic Light-Activated Ion Channels for Optogenetic Activation and Inhibition. Front Neurosci 12:643.

Bergs A, Schultheis C, Fischer E, Tsunoda SP, Erbguth K, Husson SJ, Govorunova E, Spudich JL, Nagel G, Gottschalk A, Liewald JF (2018) Rhodopsin optogenetic toolbox v2.0 for light-sensitive excitation and inhibition in Caenorhabditis elegans. PloS one 13:e0191802.

Bernal Sierra YA, Rost BR, Pofahl M, Fernandes AM, Kopton RA, Moser S, Holtkamp D, Masala N, Beed P, Tukker JJ, Oldani S, Bonigk W, Kohl P, Baier H, Schneider-Warme F, Hegemann P, Beck H, Seifert R, Schmitz D (2018) Potassium channel-based optogenetic silencing. Nature communications 9:4611.

Berndt A, Lee SY, Ramakrishnan C, Deisseroth K (2014) Structure-guided transformation of channelrhodopsin into a light-activated chloride channel. Science 344:420-424.

Berndt A, Yizhar O, Gunaydin LA, Hegemann P, Deisseroth K (2009) Bi-stable neural state switches. Nat Neurosci 12:229-234.

Berndt A, Lee SY, Wietek J, Ramakrishnan C, Steinberg EE, Rashid AJ, Kim H, Park S, Santoro A, Frankland PW, lyer SM, Pak S, Ahrlund-Richter S, Delp SL, Malenka RC, Josselyn SA, Carlen M, Hegemann P, Deisseroth K (2016) Structural foundations of optogenetics: Determinants of channelrhodopsin ion selectivity. Proc Natl Acad Sci U S A 113:822-829.

Chow BY, Han X, Dobry AS, Qian X, Chuong AS, Li M, Henninger MA, Belfort GM, Lin Y, Monahan PE, Boyden ES (2010) High-performance genetically targetable optical neural silencing by light-driven proton pumps. Nature 463:98-102.

Chuong AS et al. (2014) Noninvasive optical inhibition with a red-shifted microbial rhodopsin. Nat Neurosci 17:1123-1129.

Copits BA et al. (2021) A photoswitchable GPCR-based opsin for presynaptic inhibition. Neuron 109:1791-1809 e1711.

Dawydow A, Gueta R, Ljaschenko D, Ullrich S, Hermann M, Ehmann N, Gao S, Fiala A, Langenhan T, Nagel G, Kittel RJ (2014) Channelrhodopsin-2-XXL, a powerful optogenetic tool for low-light applications. Proc Natl Acad Sci U S A 111:13972-13977.

Duan XD, Nagel G, Gao SQ (2019) Mutated Channelrhodopsins with Increased Sodium and Calcium Permeability. Appl Sci-Basel 9.

Gee CE, Ohmert I, Wiegert JS, Oertner TG (2017) Preparation of Slice Cultures from Rodent Hippocampus. Cold Spring Harbor protocols 2017:pdb prot094888.

Ghosh DD, Lee D, Jin X, Horvitz HR, Nitabach MN (2021) C. elegans discriminates colors to guide foraging. Science 371:1059-1063. 
Gong X et al. (2020) An Ultra-Sensitive Step-Function Opsin for Minimally Invasive Optogenetic Stimulation in Mice and Macaques. Neuron 107:38-51 e38.

Govorunova EG, Sineshchekov OA, Janz R, Liu X, Spudich JL (2015) NEUROSCIENCE. Natural light-gated anion channels: A family of microbial rhodopsins for advanced optogenetics. Science 349:647-650.

Govorunova EG, Sineshchekov OA, Li H, Wang Y, Brown LS, Spudich JL (2020) RubyACRs, non-algal anion channelrhodopsins with highly red-shifted absorption. bioRxiv:2020.2004.2015.043158.

Govorunova EG, Sineshchekov OA, Rodarte EM, Janz R, Morelle O, Melkonian M, Wong GK, Spudich JL (2017) The Expanding Family of Natural Anion Channelrhodopsins Reveals Large Variations in Kinetics, Conductance, and Spectral Sensitivity. Scientific reports 7:43358.

Govorunova EG, Sineshchekov OA, Hemmati R, Janz R, Morelle O, Melkonian M, Wong GK, Spudich JL (2018) Extending the Time Domain of Neuronal Silencing with Cryptophyte Anion Channelrhodopsins. eNeuro 5.

Govorunova EG, Gou Y, Sineshchekov OA, Li H, Wang Y, Brown LS, Xue M, Spudich JL (2021) Kalium rhodopsins: Natural light-gated potassium channels. bioRxiv:2021.2009.2017.460684.

Gradinaru V, Zhang F, Ramakrishnan C, Mattis J, Prakash R, Diester I, Goshen I, Thompson KR, Deisseroth K (2010) Molecular and cellular approaches for diversifying and extending optogenetics. Cell 141:154-165.

Grimm C, Vierock J, Hegemann P, Wietek J (2017) Whole-cell Patch-clamp Recordings for Electrophysiological Determination of Ion Selectivity in Channelrhodopsins. J Vis Exp.

Groth AC, Fish M, Nusse R, Calos MP (2004) Construction of transgenic Drosophila by using the site-specific integrase from phage phiC31. Genetics 166:1775-1782.

Hu C, Petersen M, Hoyer N, Spitzweck B, Tenedini F, Wang D, Gruschka A, Burchardt LS, Szpotowicz E, Schweizer M, Guntur AR, Yang CH, Soba P (2017) Sensory integration and neuromodulatory feedback facilitate Drosophila mechanonociceptive behavior. Nat Neurosci 20:1085-1095.

Kato HE, Zhang F, Yizhar O, Ramakrishnan C, Nishizawa T, Hirata K, Ito J, Aita Y, Tsukazaki T, Hayashi S, Hegemann P, Maturana AD, Ishitani R, Deisseroth K, Nureki O (2012) Crystal structure of the channelrhodopsin light-gated cation channel. Nature 482:369374.

Kato HE, Kim YS, Paggi JM, Evans KE, Allen WE, Richardson C, Inoue K, Ito S, Ramakrishnan C, Fenno LE, Yamashita K, Hilger D, Lee SY, Berndt A, Shen K, Kandori H, Dror RO, Kobilka BK, Deisseroth K (2018) Structural mechanisms of selectivity and gating in anion channelrhodopsins. Nature 561:349-354.

Keene AC, Sprecher SG (2012) Seeing the light: photobehavior in fruit fly larvae. Trends Neurosci 35:104-110.

Kim YS, Kato HE, Yamashita K, Ito S, Inoue K, Ramakrishnan C, Fenno LE, Evans KE, Paggi JM, Dror RO, Kandori H, Kobilka BK, Deisseroth K (2018) Crystal structure of the natural anion-conducting channelrhodopsin GtACR1. Nature 561:343-348.

Klapoetke NC et al. (2014) Independent optical excitation of distinct neural populations. Nat Methods 11:338-346.

Kleis P, Paschen E, Haussler U, Bernal Sierra YA, Haas CA (2022) Long-term in vivo application of a potassium channel-based optogenetic silencer in the healthy and epileptic mouse hippocampus. BMC Biol 20:18. 
Kralj JM, Douglass AD, Hochbaum DR, Maclaurin D, Cohen AE (2011) Optical recording of action potentials in mammalian neurons using a microbial rhodopsin. Nat Methods 9:9095.

Levi D (1944) Aion. Hesperia 13.

Li N, Chen S, Guo ZV, Chen H, Huo Y, Inagaki HK, Chen G, Davis C, Hansel D, Guo C, Svoboda K (2019) Spatiotemporal constraints on optogenetic inactivation in cortical circuits. eLife 8.

Lim ST, Antonucci DE, Scannevin RH, Trimmer JS (2000) A novel targeting signal for proximal clustering of the Kv2.1 K+ channel in hippocampal neurons. Neuron 25:385-397.

Mahn M, Prigge M, Ron S, Levy R, Yizhar O (2016) Biophysical constraints of optogenetic inhibition at presynaptic terminals. Nat Neurosci 19:554-556.

Mahn M, Gibor L, Patil P, Cohen-Kashi Malina K, Oring S, Printz Y, Levy R, Lampl I, Yizhar O (2018) High-efficiency optogenetic silencing with soma-targeted anion-conducting channelrhodopsins. Nature communications 9:4125.

Mahn M et al. (2021) Efficient optogenetic silencing of neurotransmitter release with a mosquito rhodopsin. Neuron 109:1621-1635 e1628.

Malyshev AY, Roshchin MV, Smirnova GR, Dolgikh DA, Balaban PM, Ostrovsky MA (2017) Chloride conducting light activated channel GtACR2 can produce both cessation of firing and generation of action potentials in cortical neurons in response to light. Neurosci Lett 640:76-80.

Mattis J, Tye KM, Ferenczi EA, Ramakrishnan C, O'Shea DJ, Prakash R, Gunaydin LA, Hyun M, Fenno LE, Gradinaru V, Yizhar O, Deisseroth K (2011) Principles for applying optogenetic tools derived from direct comparative analysis of microbial opsins. Nat Methods 9:159-172.

Messier JE, Chen H, Cai ZL, Xue M (2018) Targeting light-gated chloride channels to neuronal somatodendritic domain reduces their excitatory effect in the axon. eLife 7.

Mohammad F, Stewart JC, Ott S, Chlebikova K, Chua JY, Koh TW, Ho J, Claridge-Chang A (2017) Optogenetic inhibition of behavior with anion channelrhodopsins. Nat Methods 14:271-274.

Nack M, Radu I, Gossing M, Bamann C, Bamberg E, von Mollard GF, Heberle J (2010) The DC gate in Channelrhodopsin-2: crucial hydrogen bonding interaction between $\mathrm{C} 128$ and D156. Photoch Photobio Sci 9:194-198.

Oppermann J, Fischer P, Silapetere A, Liepe B, Rodriguez-Rozada S, Flores-Uribe J, Peter E, Keidel A, Vierock J, Kaufmann J, Broser M, Luck M, Bartl F, Hildebrandt P, Wiegert JS, Beja O, Hegemann P, Wietek J (2019) MerMAIDs: a family of metagenomically discovered marine anion-conducting and intensely desensitizing channelrhodopsins. Nature communications 10:3315.

Owen SF, Liu MH, Kreitzer AC (2019) Thermal constraints on in vivo optogenetic manipulations. Nat Neurosci 22:1061-1065.

Pugh JR, Jahr CE (2011) Axonal GABAA receptors increase cerebellar granule cell excitability and synaptic activity. J Neurosci 31:565-574.

Qian Y, Cosio DMO, Piatkevich KD, Aufmkolk S, Su WC, Celiker OT, Schohl A, Murdock MH, Aggarwal A, Chang YF, Wiseman PW, Ruthazer ES, Boyden ES, Campbell RE (2020) Improved genetically encoded near-infrared fluorescent calcium ion indicators for in vivo imaging. PLoS Biol 18:e3000965.

Raimondo JV, Kay L, Ellender TJ, Akerman CJ (2012) Optogenetic silencing strategies differ in their effects on inhibitory synaptic transmission. Nat Neurosci 15:1102-1104. 
Schindelin J, Arganda-Carreras I, Frise E, Kaynig V, Longair M, Pietzsch T, Preibisch S, Rueden C, Saalfeld S, Schmid B, Tinevez JY, White DJ, Hartenstein V, Eliceiri K, Tomancak P, Cardona A (2012) Fiji: an open-source platform for biological-image analysis. Nat Methods 9:676-682.

Sineshchekov OA, Govorunova EG, Li H, Spudich JL (2015) Gating mechanisms of a natural anion channelrhodopsin. Proc Natl Acad Sci U S A 112:14236-14241.

Sineshchekov OA, Li H, Govorunova EG, Spudich JL (2016) Photochemical reaction cycle transitions during anion channelrhodopsin gating. Proc Natl Acad Sci U S A 113:E19932000.

Stachniak TJ, Ghosh A, Sternson SM (2014) Chemogenetic synaptic silencing of neural circuits localizes a hypothalamus-->midbrain pathway for feeding behavior. Neuron 82:797-808.

Stujenske JM, Spellman T, Gordon JA (2015) Modeling the Spatiotemporal Dynamics of Light and Heat Propagation for In Vivo Optogenetics. Cell reports 12:525-534.

Szabadics J, Varga C, Molnar G, Olah S, Barzo P, Tamas G (2006) Excitatory effect of GABAergic axo-axonic cells in cortical microcircuits. Science 311:233-235.

Turecek R, Trussell LO (2001) Presynaptic glycine receptors enhance transmitter release at a mammalian central synapse. Nature 411:587-590.

Volkov O, Kovalev K, Polovinkin V, Borshchevskiy V, Bamann C, Astashkin R, Marin E, Popov A, Balandin T, Willbold D, Buldt G, Bamberg E, Gordeliy V (2017) Structural insights into ion conduction by channelrhodopsin 2. Science 358.

Wiegert JS, Gee CE, Oertner TG (2017a) Single-Cell Electroporation of Neurons. Cold Spring Harbor protocols 2017:pdb prot094904.

Wiegert JS, Mahn M, Prigge M, Printz Y, Yizhar O (2017b) Silencing Neurons: Tools, Applications, and Experimental Constraints. Neuron 95:504-529.

Wietek J, Broser M, Krause BS, Hegemann P (2016) Identification of a Natural Green Light Absorbing Chloride Conducting Channelrhodopsin from Proteomonas sulcata. J Biol Chem 291:4121-4127.

Wietek J, Beltramo R, Scanziani M, Hegemann P, Oertner TG, Wiegert JS (2015) An improved chloride-conducting channelrhodopsin for light-induced inhibition of neuronal activity in vivo. Scientific reports 5:14807.

Wietek J, Rodriguez-Rozada S, Tutas J, Tenedini F, Grimm C, Oertner TG, Soba P, Hegemann P, Wiegert JS (2017) Anion-conducting channelrhodopsins with tuned spectra and modified kinetics engineered for optogenetic manipulation of behavior. Scientific reports 7:14957.

Wietek J, Wiegert JS, Adeishvili N, Schneider F, Watanabe H, Tsunoda SP, Vogt A, Elstner M, Oertner TG, Hegemann P (2014) Conversion of channelrhodopsin into a light-gated chloride channel. Science 344:409-412.

Wright R, Raimondo JV, Akerman CJ (2011) Spatial and temporal dynamics in the ionic driving force for $\operatorname{GABA}(A)$ receptors. Neural Plast 2011:728395.

Xiang Y, Yuan Q, Vogt N, Looger LL, Jan LY, Jan YN (2010) Light-avoidance-mediating photoreceptors tile the Drosophila larval body wall. Nature 468:921-926.

Yizhar O, Fenno LE, Prigge M, Schneider F, Davidson TJ, O'Shea DJ, Sohal VS, Goshen I, Finkelstein J, Paz JT, Stehfest K, Fudim R, Ramakrishnan C, Huguenard JR, Hegemann $P$, Deisseroth K (2011) Neocortical excitation/inhibition balance in information processing and social dysfunction. Nature 477:171-178. 

G, Gottschalk A, Deisseroth K (2007) Multimodal fast optical interrogation of neural circuitry. Nature 446:633-639.

Zhong L, Hwang RY, Tracey WD (2010) Pickpocket is a DEG/ENaC protein required for mechanical nociception in Drosophila larvae. Curr Biol 20:429-434. 


\section{Supplemental Figures}
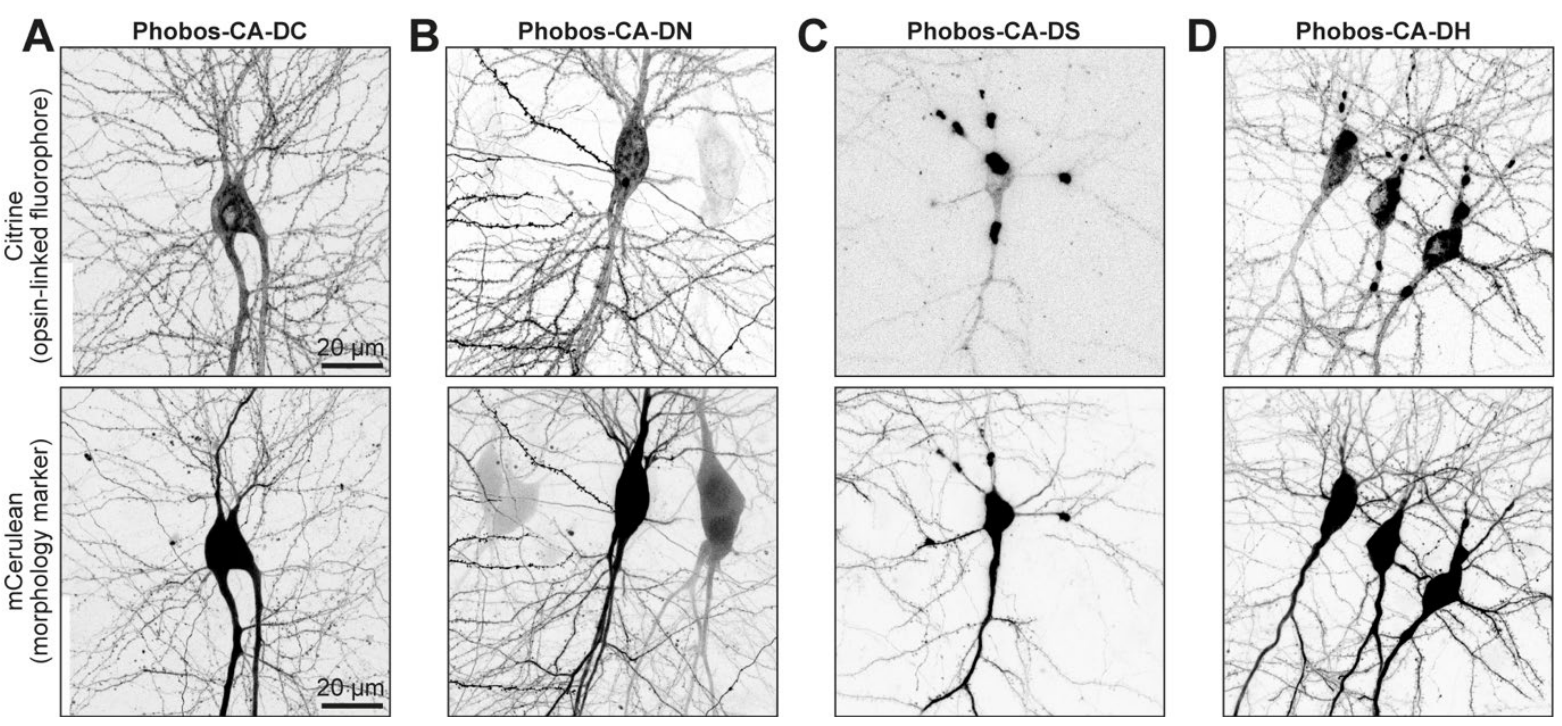

Figure S1. Neuronal expression of Phobos ${ }^{\mathrm{CA}}$ D156 mutants. Maximum-intensity projection images of two-photon stacks showing expression of Phobos ${ }^{\mathrm{CA}}-\mathrm{D} 156 \mathrm{C}$ (A), Phobos ${ }^{\mathrm{CA}}-\mathrm{D} 156 \mathrm{~N}$ (B), Phobos ${ }^{\mathrm{CA}}-$ D156S (C), and Phobos ${ }^{\mathrm{CA}}$-D156H (D) in CA1 pyramidal neurons after single-cell electroporation in organotypic hippocampal slice cultures. Fluorescence intensity is shown as inverted gray values. Opsincitrine fluorescence (top row) was mainly localized at the plasma membrane in Phobos ${ }^{\mathrm{CA}}-\mathrm{D} 156 \mathrm{C}$ (A) and Phobos ${ }^{\text {CA }}-\mathrm{D} 156 \mathrm{~N}$ (B) expressing cells. However, Phobos ${ }^{\mathrm{CA}}-\mathrm{D} 156 \mathrm{~S}$ (C) and Phobos ${ }^{\mathrm{CA}}-\mathrm{D} 156 \mathrm{H}$ (D) expressing neurons showed poor trafficking and strong protein accumulation in the soma. mCerulean was co-electroporated together with all opsin variants and served as a morphology marker (bottom row). 
A
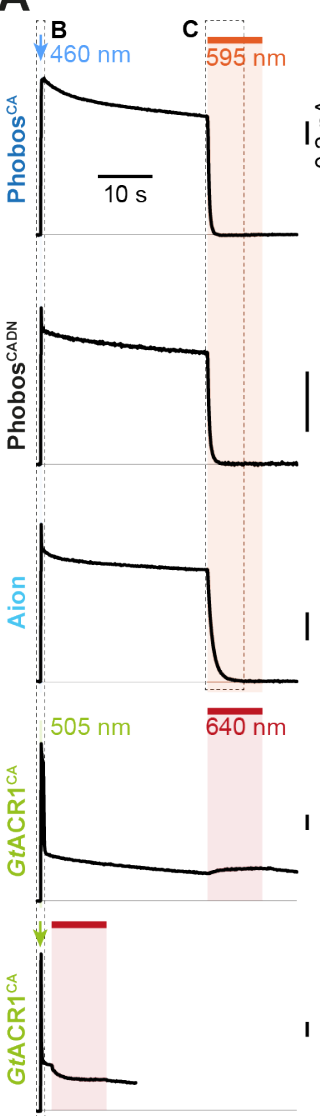

B
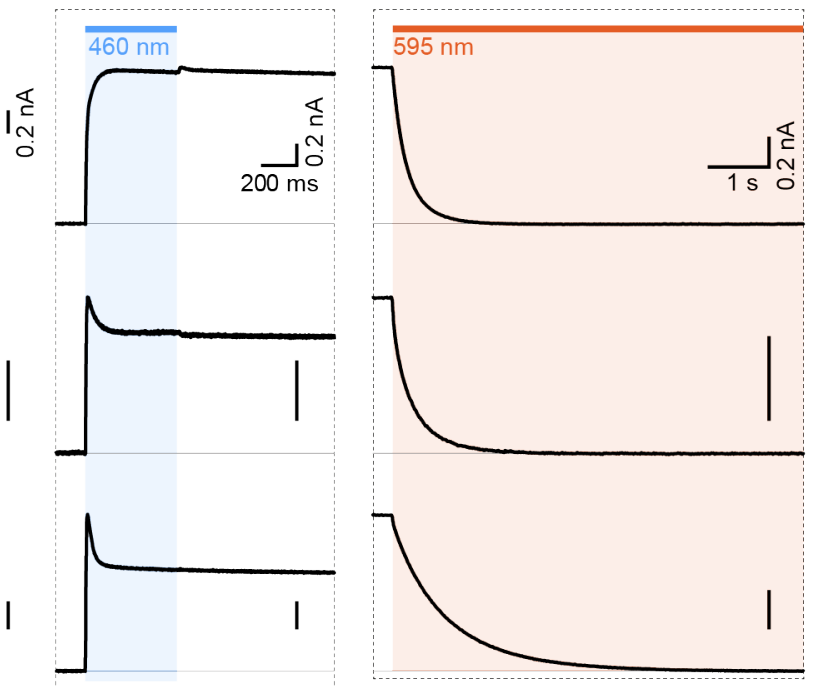

C

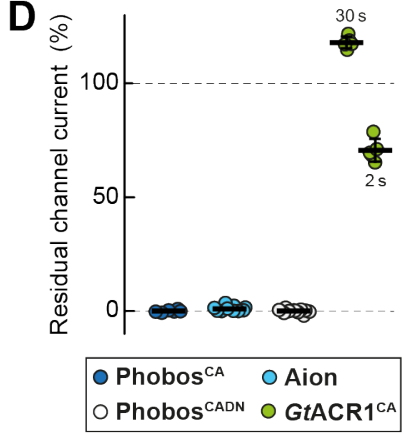

E

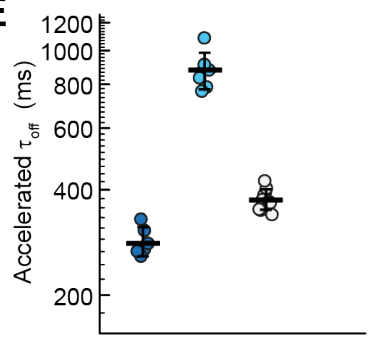

Figure S2. Photoresponse of slow-cycling ACR variants. (A) Representative current traces of kinetically modified Phobos ${ }^{\mathrm{CA}}$ variants and GtACR $1^{\mathrm{CA}}$. ACR variants were illuminated with $500 \mathrm{~ms}$ (row 1-4) or $20 \mathrm{~ms}$ (last row) actinic light at indicated wavelengths, while termination of photocurrents was accelerated with orange or red light for $10 \mathrm{~s}$ as indicated. (B) and (C) temporally expanded photocurrent traces as shown in (A) showing different modes of inactivation (B) and accelerated closing kinetics of Phobos $^{\mathrm{CA}}$ variants (C). (D) Quantification of the residual photocurrent after orange or red-light application. While GtACR $1^{C A}$ showed a $30 \%$ photocurrent reduction when red light was applied $2 \mathrm{~s}$ post initial activation, application after $30 \mathrm{~s}$ caused partial re-opening of the channel. Phobos ${ }^{\mathrm{CA}}$ variants could be fully closed by orange light. (E) Quantification of the accelerated channel closing of Phobos ${ }^{\mathrm{CA}}$ variants with orange light. 

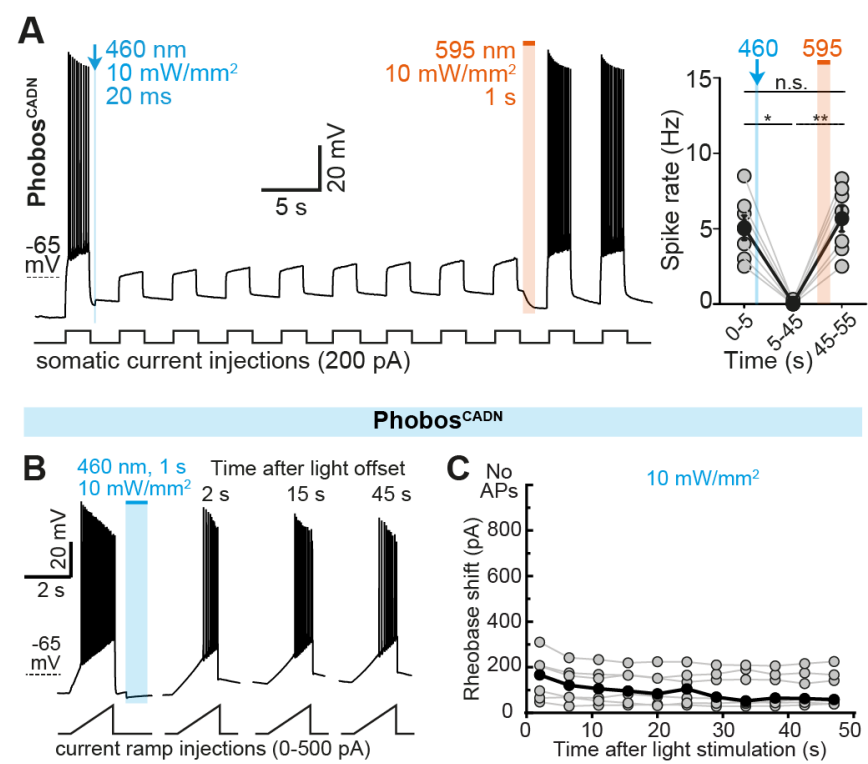

Phobos ${ }^{\text {CADN }}$
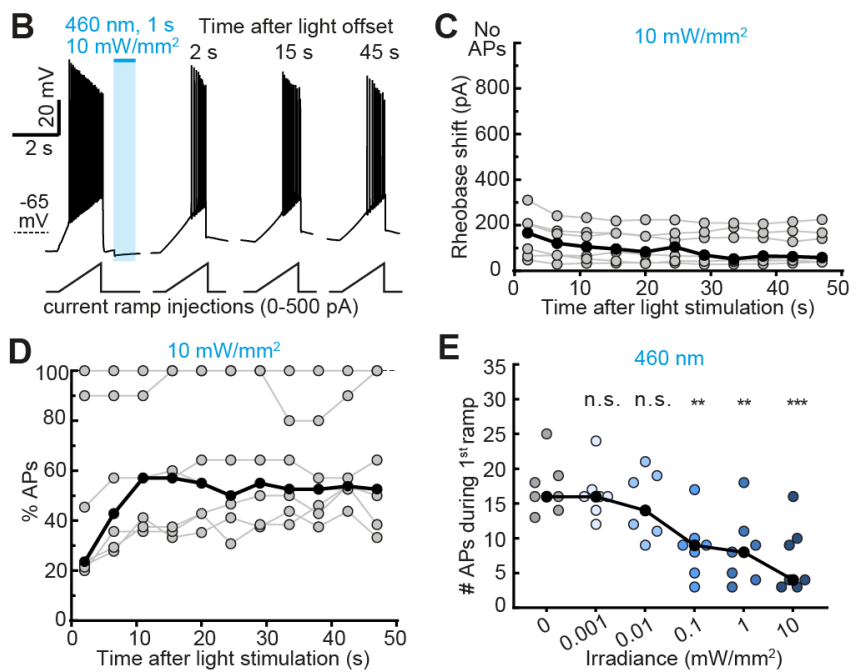

Figure S3. Silencing efficiency of Phobos ${ }^{\text {CADN }}$ in CA1 pyramidal neurons. (A) Left: Membrane voltage trace showing reversible suppression of depolarization-induced APs by photoswitching Phobos ${ }^{\mathrm{CADN}}$ between open and closed state with a blue $\left(460 \mathrm{~nm}, 20 \mathrm{~ms}, 10 \mathrm{~mW} / \mathrm{mm}^{2}\right)$ and orange light pulse (595 nm, $\left.1 \mathrm{~s}, 10 \mathrm{~mW} / \mathrm{mm}^{2}\right)$, respectively. Right: Quantification of spike rate during current injection at indicated time intervals: before channel opening (0-5 s), after channel opening (5-45s), and after channel closing (45-55 s) in Phobos ${ }^{\mathrm{CADN}}$-expressing CA1 neurons $(\mathrm{n}=7$ cells). Grey circles represent single measurement data points and black circles correspond to mean values \pm SEM, Friedman test, * $p$ $<0.05,{ }^{* *} p<0.01,{ }^{* * *} p<0.001$, n.s. $=$ not significant. (B) Current ramps were injected into Phobos ${ }^{\text {CADN }}$ expressing neurons to induce APs before and after illumination with a short blue light pulse $(460 \mathrm{~nm}, 1$ $\mathrm{s}$, irradiances from 0.001 to $10 \mathrm{~mW} / \mathrm{mm}^{2}$ ). For each ramp, the injected current at the time of the $1^{\text {st }} \mathrm{AP}$ was defined as the rheobase. Example membrane voltage traces are shown for the trial in which a light intensity of $10 \mathrm{~mW} / \mathrm{mm}^{2}$ was used. (C) Quantification of the rheobase shift and (D) the relative change in the number of current ramp-evoked APs during $47 \mathrm{~s}$ after light stimulation $\left(460 \mathrm{~nm}, 1 \mathrm{~s}, 10 \mathrm{~mW} / \mathrm{mm}^{2}\right)$ ( $n=7$ cells). (E) Relative change in the number of APs evoked during the first current ramp after opening of Phobos ${ }^{\text {CADN }}$ with $1 \mathrm{~s}$ blue light at indicated irradiances. Significant AP block was achieved at 0.1 $\mathrm{mW} / \mathrm{mm}^{2}$ ( $\mathrm{n}=7$ cells). For (C-E) grey circles represent single measurement data points and black circles correspond to medians, Friedman test, ${ }^{*} p<0.05,{ }^{* *} p<0.01,{ }^{* * *} p<0.001$, n.s. $=$ not significant. 

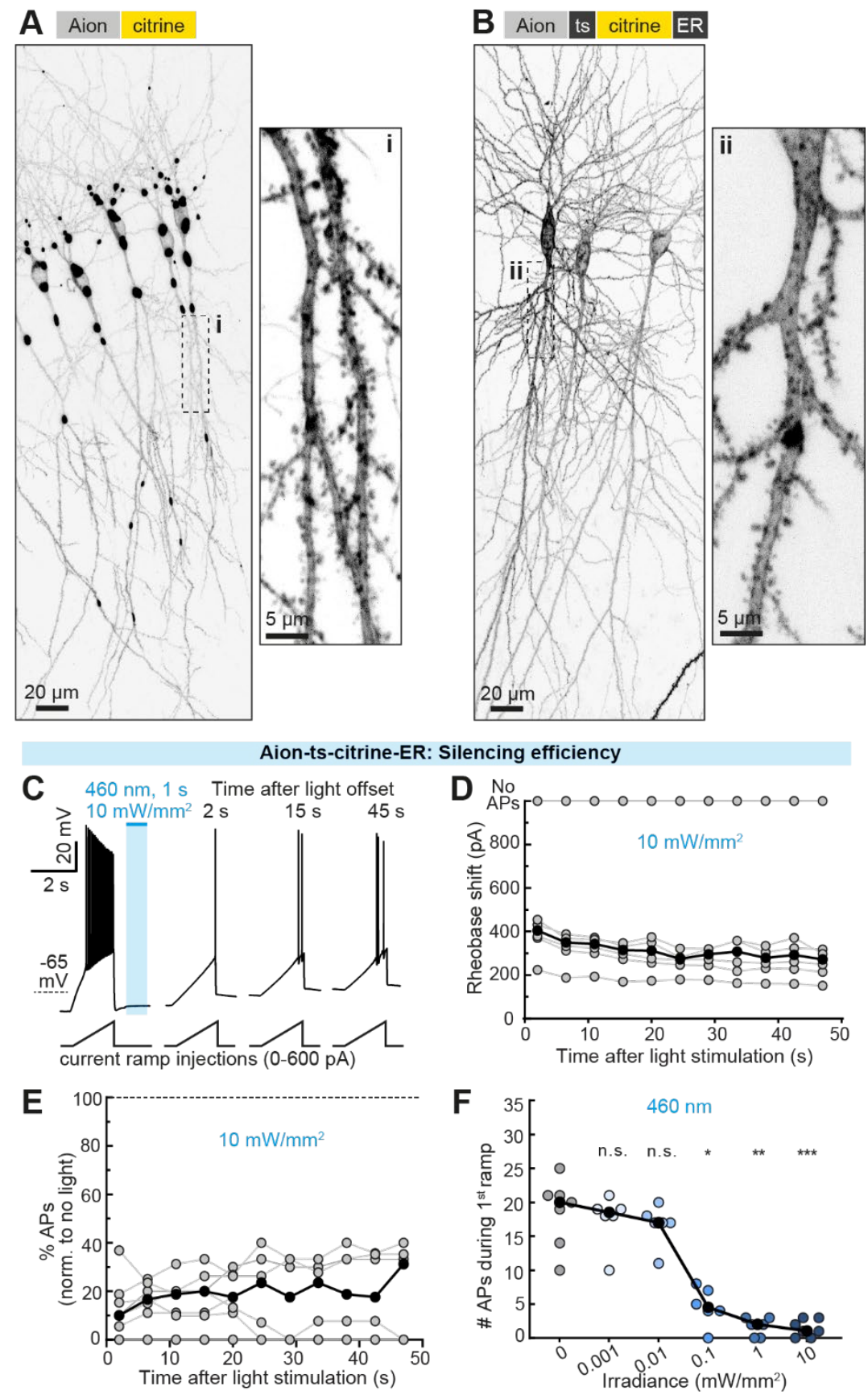

Figure S4. Aion trafficking optimization. (A) Maximum-intensity projection image of two-photon stacks showing overexpression of Aion-citrine in CA1 pyramidal neurons after single-cell electroporation in organotypic hippocampal slice cultures. In these example cells, opsin accumulations were very prominent in the soma, basal dendrites and in the proximal region of the main apical dendrite. Inset shows magnified view of a portion of the main apical dendrite with no accumulations and efficient membrane localization. (B) Maximum-intensity projection image of two-photon stacks of neurons expressing Aion-ts-citrine-ER. In this case, efficient membrane localization with no opsin accumulations was observed throughout the cells. Inset shows magnified view of the main apical dendrite. (C) Example membrane voltage traces in response to current ramps injected into Aion-ts-citrine-ER-expressing neurons before and after illumination with a $1 \mathrm{~s}$ blue light pulse. For each ramp, the injected current at the time of the first action potential was defined as the rheobase. (D) Quantification of the rheobase shift and $(E)$ the relative change in the number of current ramp-evoked APs over 1 minute after light stimulation $\left(460 \mathrm{~nm}, 1 \mathrm{~s}, 10 \mathrm{~mW} / \mathrm{mm}^{2}\right)(\mathrm{n}=6$ cells). (F) Change in the number of APs evoked during the first current ramp after opening of Aion-ts-citrine-ER with $1 \mathrm{~s}$ blue light at indicated irradiances. 
Significant AP block was achieved at $0.1 \mathrm{~mW} / \mathrm{mm}^{2}$ ( $\mathrm{n}=7$ cells). In all plots grey circles (or blue in F) represent single measurement data points and black circles correspond to medians, Friedman test, ${ }^{*} p$ $<0.05,{ }^{* *} \mathrm{p}<0.01,{ }^{* * *} \mathrm{p}<0.001$, n.s. $=$ not significant.
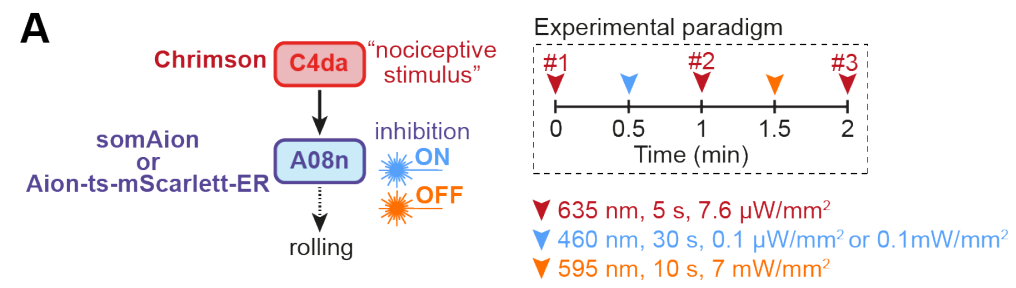

$$
\text { B }
$$

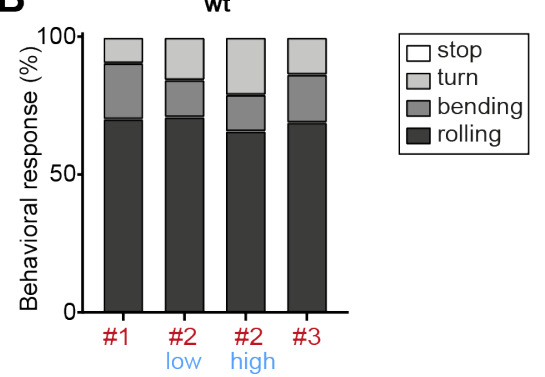

C

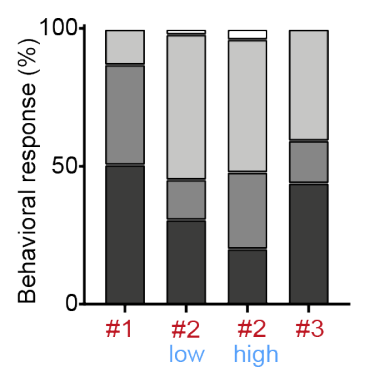

20x somAion

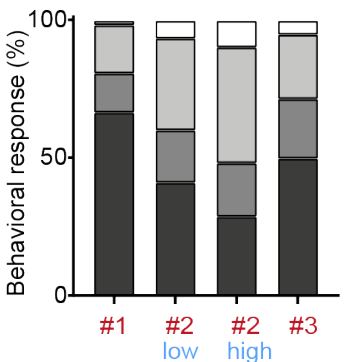

D

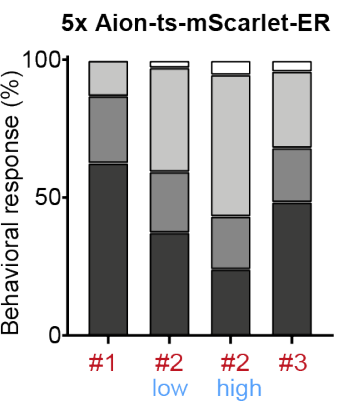

20x Aion-ts-mScarlet-ER

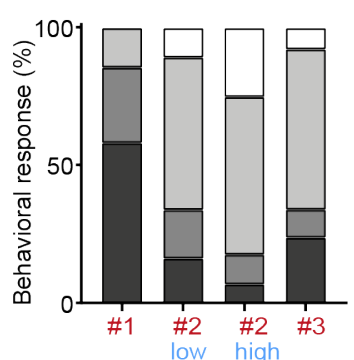

Figure S5. Inhibition of Drosophila melanogaster A08n neurons with trafficking-optimized variants of Aion. (A) All-optical paradigm for inhibition of A08n neurons with somAion or Aion-tsmScarlet-ER and activation of C4da neurons with CsChrimson in Drosophila larvae. (B-D) Behavioral responses to CsChrimson activation in C4da neurons at the indicated time points in wt larvae (B) and transgenic larvae expressing somAion (C, left: 5xUAS, right 20xUAS) or Aion-ts-mScarlet-ER (D, left: 5xUAS, right 20xUAS) in A08n neurons. All Aion variants were able to significantly inhibit nociceptive behavior after a low $\left(0.1 \mu \mathrm{m} / \mathrm{mm}^{2}\right)$ or high intensity $\left(0.1 \mathrm{~mW} / \mathrm{mm}^{2}\right)$ blue light stimulus, which could be (at least partially) reversed by orange light. 